NASA Technical Memorandum 100694

\title{
Tidal Estimation in the Pacific with Application to SEASAT Altimetry
}

Braulio V. Sanchez

Goddard Space Flight Center

Greenbelt, Maryland

and

David E. Cartwright

National Academy of Sciences

Washington, D.C.

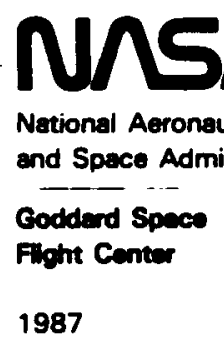




\section{TIDAL ESTIMATION IN THE PACIFIC WITH APPLICATION TO SEASAT ALTIMETRY}

\section{INTRODUCTION}

This is the second report of an investigation concerning the application of Proudman functions to the estimation of tidal components in the world's oceans. The first report presented results obtained in the AtlanticIndian Oceans (Sanchez et al., 1986).

This investigation focuses on the Pacific basin and incorporates some aspects which were lacking in the previous investigation in the Atlantic-Indian Oceans.

The application of satellite altimetry to the investigation of dynamical phenomena in the oceans is becoming a well-defined engineering and scientific field. The ocean tides produced by the gravitational attraction of the moon and the sun constitute an interesting and important aspect of these investigations. The dynamical response of the oceans to the astronomical forcing functions is not an equilibrium one. This is easily understood in the context of the normal modes of the fluid basins involved, which have periodicities spanning the range of the forcing functions. This is certainly true for the gravitational normal modes modified by rotation, in relation to the diurnal and semidiumal components of the tidal potential. The rotational modes modified by gravity have longer periods; they might play a role in the response of the oceans to seasonal winds and other phenomena associated with ocean circulation.

The frequency spectrum and space structure of the normal modes of the world's oceans are determined by the configuration of their boundaries and their bathymetry, as well as by the physical properties of the fluid, such as density and viscosity. The actual detection of the free periods of oscillation of the oceans from the analysis of available data remains an open area for investigation. The reader is referred to Platzman, et al. (1981), and to Luther (1983), for excellent discussions of this problem, including further references. The numerical computation of normal modes for mathematical models of the ocean basins is an area where contributions have been made by many investigators. The following is not intended to be an exhaustive historical review, but only a sampling of the literature: the theoretical papers by Longuet-Higgins (1968), LonguetHiggins and Pond (1970), and Christensen (1973), which dealt with the analytical eigensolutions of the Laplace Tidal Equations (LTE) for rotating spherical and hemispherical regions, Gotlib and Kagan (1980, 1982) reconstructed the spatial structure of the $\mathrm{K}_{1}$ and $0_{1}$ tides from eight eigenfunctions of the LTE with periods in the range 17-30 h; they used 639 data points from coastal and island stations. Webb (1980) studied the role of resonance and friction in the tidal response and energy dissipation. He used a flat-bottomed, hemispherical ocean, centered at the Equator. Platzman (1978, 1984), and Platzman, et al. (1981), computed a range of normal modes for the world oceans and used them to synthesize some of the diurnal and semidiumal tides. In a more limited geographical scale, Wubber and Krauss (1979) computed periods and structures of the gravitational free oscillations in the Baltic Sea; Schwab and Rao (1983) computed several of the lowest gravitational normal modes in the Mediterranean-Adriatic system.

The objectives of this investigation are not limited to the numerical computation of normal modes; the main goal is the exploration of the applicability of the Proudman functions as a basis for the analysis of tidal data. However, the computation of the modes is still considered to be of sufficient scientific interest in itself to warrant the partial presentation of the results. In addition, the computation of the forced solutions and the potential energy spectra for the different tidal components contribute to the understanding of the method and lends unity to its presentation. The detailed mathematical formulation of the method can be found in previous publications (Sanchez et al., 1985, 1986). The theoretical foundation is Proudman's theory (1918) as formulated by Rao (1966). The theory provides the formalism for calculation of the gravitational (first class) modes and the rotational (second class or Rossby wave) normal modes of irregularly-shaped basins with realistic bathymetry.

The method requires the solution of two elliptic partial differential equations with second-order operators, which are simpler than the tidal operator. The boundary conditions correspond to vanishing of the 
stream function and normal derivative of the velocity potential. The elliptic operators are numerically represented in finite difference form; the grid used is a Richardson lattice, which preserves self-adjointness. The solutions yield the velocity and surface height fields in terms of orthogonal functions with time-dependent coefficients. These functions are then substituted into Laplace's tidal equations: if the homogeneous equations are used, one obtains the normal modes; if the forcing terms are included, then the forced solution is obtained. In both cases, the solution is obtained numerically. The surface height field is only dependent on the velocity potential orthogonal functions, also referred to as Proudman functions. They correspond to the gravitational normal modes at zero rotation. The expansion coefficients of these functions can be estimated in a least-squares sense from available selected tidal measurements. It is possible to use the normal modes as a basis for the interpolation (Woodworth and Cartwright, 1986). We believe the adoption of the Proudman functions as a basis offers the advantage of simplicity, since to compute these functions, it is only necessary to solve the equation

$$
\nabla \cdot h \nabla \phi_{\gamma}=-\lambda_{\gamma} \phi_{\gamma}
$$

subject to the boundary condition

$$
\mathrm{h} \frac{\partial \phi_{\gamma}}{\partial \mathrm{n}}=0
$$

where

$$
\begin{aligned}
\mathrm{h}: & \text { variable depth of the fluid in equilibrium } \\
\phi_{\gamma}: & \text { eigenfunctions of the velocity potential } \\
\lambda_{\gamma}: & \text { corresponding eigenvalue } \\
\frac{\partial \phi_{\gamma}}{\partial \mathrm{n}}: & \text { gradient in the direction normal to the boundary. }
\end{aligned}
$$

Besides simplicity, the Proudman functions offer the advantage of being free of the dynamic prejudice introduced by factors such as friction. Also, they are dependent only on the shape and depth of the particlar basin, so they have to be computed only once when analyzing different tidal constituents.

\section{NORMAL MODES AND FORCED SOLUTIONS}

The numerical solutions were obtained by means of finite differences using a $6^{\circ} \times 6^{\circ}$ Richardson lattice. There are 510 velocity potential points $(\phi)$ and 455 stream function points $(\psi)$ in the Pacific basin. The eigenfunctions of the velocity potential, or Proudman functions, correspond to the gravitational normal modes of the basin at zero rotation. The periods of oscillation of the slowest modes are given in the first column of Table 1. These modes also have the largest space scales. The second column of Table 1 exhibits the periods of the slowest 30 gravitational modes modified by rotation. They all have kinetic:potential energy ratios close to unity, as shown in the last column. The normal mode solution was obtained by including the lowest 150 eigenfunctions from each field $(\phi$ and $\psi)$. Platzman (1978) computed normal modes for the world oceans using a finite-element technique with triangular grid elements having an average area equal to that of a $4.5^{\circ}$ equatorial square. A direct comparison with his results must consider the fact that our model has artificial boundaries across the Drake Passage and the Tasman Plateau; a direct consequence of these barriers is the impossibility of obtaining any circulation around Antarctica. However, some similarities in the results of these separate investigations are clearly discemible. Platzman's mode 16 with natural period 28.7 hours (Platzman, et al., 1981), which is a combination of a Pacific 1/2 wave and an Antarctic Kelvin wave, bears a strong spatial resemblance to our second gravitational mode with a period of 32.82 hours. The correspondence is verified still further by Platzman's comments concerning the configuration of this mode at zero rotation and its period of 29.9 hours when using a model of the Pacific Ocean alone. Figures $1 \mathrm{a}$ and $1 \mathrm{~b}$ show the Proudman function, and the corresponding normal mode obtained with our model. The Proudman function plot shows the contours of equal amplitude (normalized to maximum value $=100$ ). The contour of zero amplitude is the nodal line; the nodal lines remain fixed in space and the nonrotating modes have the nature of standing 
Table 1. Gravitational Modes

\begin{tabular}{|c|c|c|}
\hline \multicolumn{2}{|c|}{ Period $(\mathrm{hr})$} & \multirow{2}{*}{$\begin{array}{c}\text { Energy Ratio } \\
\text { (Kinetic/Potential) }\end{array}$} \\
\hline Nonrotational & Rotational & \\
\hline 43.91 & 43.94 & 0.97 \\
\hline 29.99 & 32.82 & 0.98 \\
\hline 26.37 & 25.16 & 1.01 \\
\hline 22.11 & 21.61 & 0.92 \\
\hline 20.63 & 20.76 & 1.01 \\
\hline 18.58 & 18.65 & 1.06 \\
\hline 17.93 & 16.70 & 0.99 \\
\hline 16.47 & 16.12 & 1.04 \\
\hline 16.10 & 15.33 & 1.00 \\
\hline 15.77 & 15.00 & 1.16 \\
\hline 14.53 & 14.21 & 1.33 \\
\hline 14.13 & 13.77 & 1.14 \\
\hline 13.18 & 12.60 & $1: 00$ \\
\hline 12.69 & 12.26 & 1.08 \\
\hline 12.46 & 11.78 & 1.23 \\
\hline 12.09 & 11.57 & 1.15 \\
\hline 11.66 & 11.28 & 1.17 \\
\hline 11.06 & 10.84 & 1.18 \\
\hline 10.92 & 10.61 & 1.07 \\
\hline 10.53 & 10.24 & 1.05 \\
\hline 10.09 & 9.95 & 1.05 \\
\hline 9.73 & 9.38 & 1.06 \\
\hline 9.51 & 9.33 & 1.17 \\
\hline 9.49 & 9.10 & 1.15 \\
\hline 9.19 & 8.99 & 1.12 \\
\hline 9.01 & 8.79 & 1.08 \\
\hline 8.80 & 8.66 & 1.10 \\
\hline 8.68 & 8.39 & 1.07 \\
\hline 8.43 & 8.21 & 1.08 \\
\hline 8.40 & 8.09 & 1.12 \\
\hline
\end{tabular}

waves. In the normal mode plot, the contours of equal amplitude and phase are given by the solid and dashed lines; the arrows indicate the sense of progression for high and low water. Platzman's mode 19 with a period of 21.2 hours resembles our third gravitational mode with four cyclonic amphidromes and the period lengthened to 25.16 hours. Figures $2 \mathrm{a}$ and $2 \mathrm{~b}$ refer to this mode. As the structures of the modes become finer, and their periods shorter, it becomes harder to establish clear cut one-to-one correspondences between the results of the two models.

The forced solutions yield the amplitude and phase fields for the various tidal components. In the context of this investigation, the forced solutions are frictionless, without self-attraction or tidal loading effects. Figures 3 and 4 show the tidal solutions obtained for the $\mathrm{M}_{2}$ and $0_{1}$ components. It is interesting to note that the $\mathrm{M}_{2}$ amphidromic pattem in the northeast Pacific resembles that obtained by Brown and Hutchinson (1981) from analysis of SEASAT and GEOS-3 altimetry data, although the resemblance of both to Schwiderski's (1983) solution, Figure 5, is not as good.

Tables 2 and 3 show the periods and potential energy percentages of the 10 most energetic modes for each of the diumal and semidiumal components. The mode with a period of 11.78 hours is the most energetic for the $\mathrm{M}_{2}$ and $\mathrm{N}_{2}$ components. For the $\mathrm{S}_{2}$ and $\mathrm{K}_{2}$ solutions, the most energetic mode has a period 


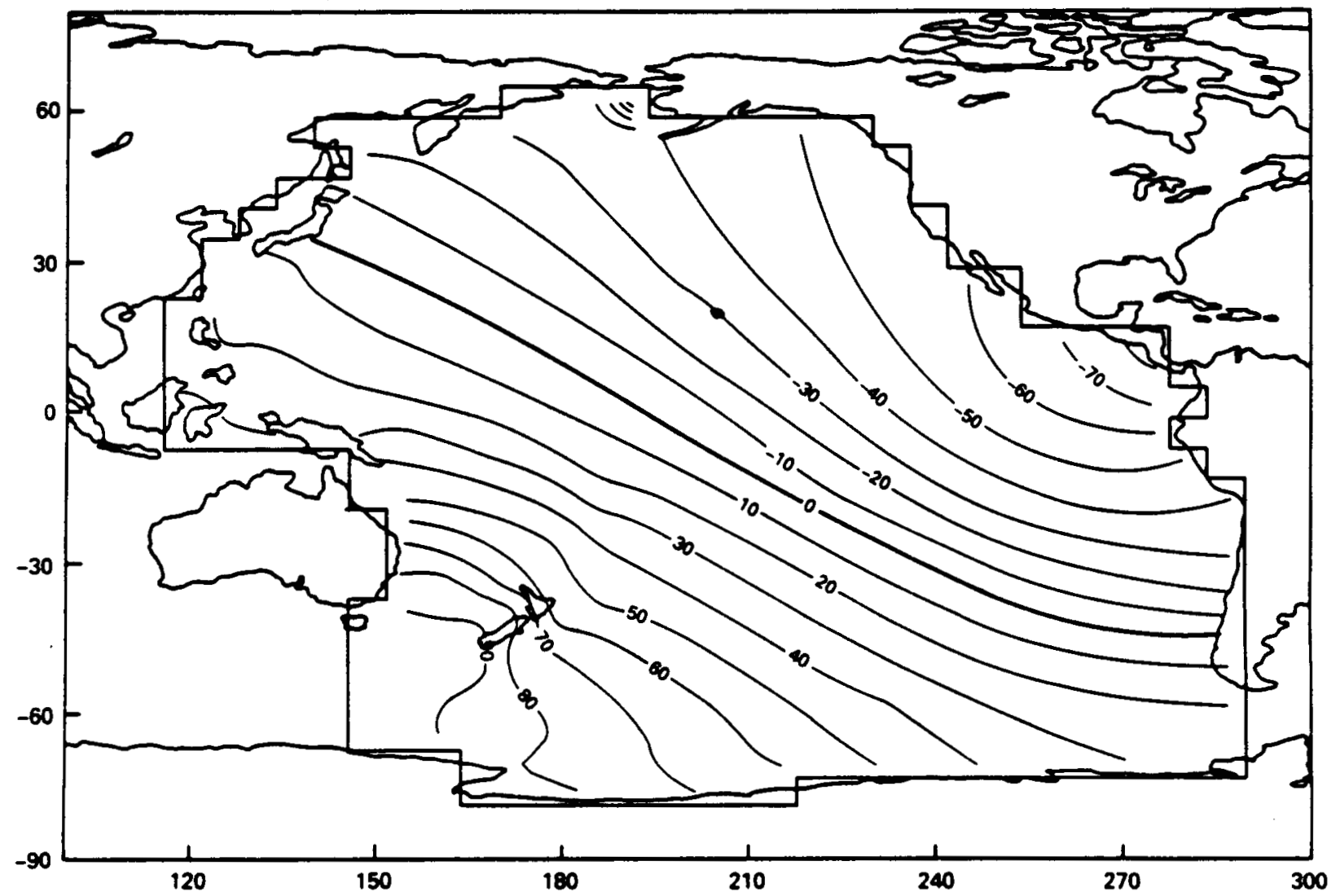

Figure 1a. Proudman function with period $=29.99$ hours. Contours of equal amplitude normalized to maximum value $=100$.

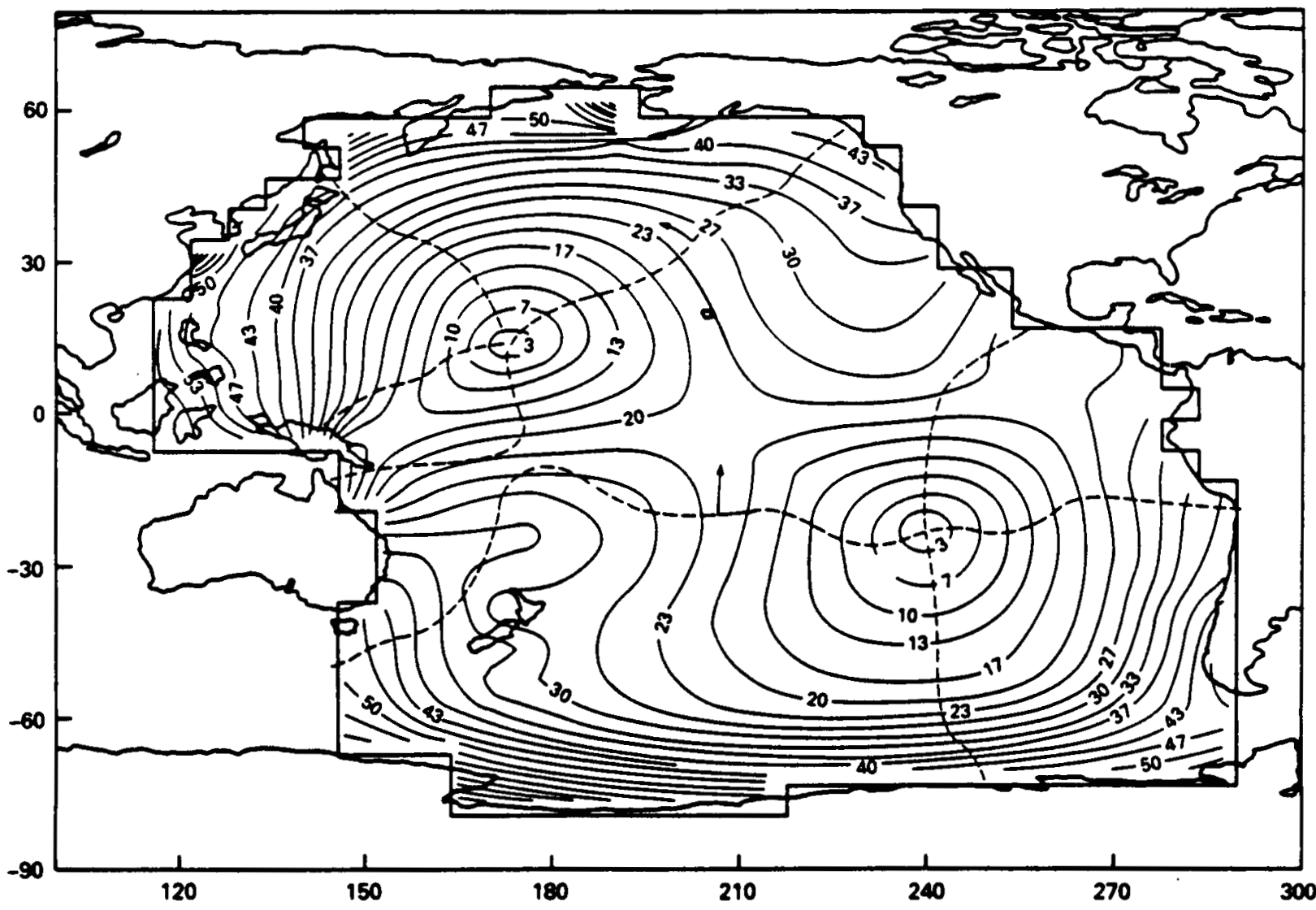

Figure 1b. Normal mode with period $=\mathbf{3 2 . 8 2}$ hours. Contours of equal amplitude and phase. 


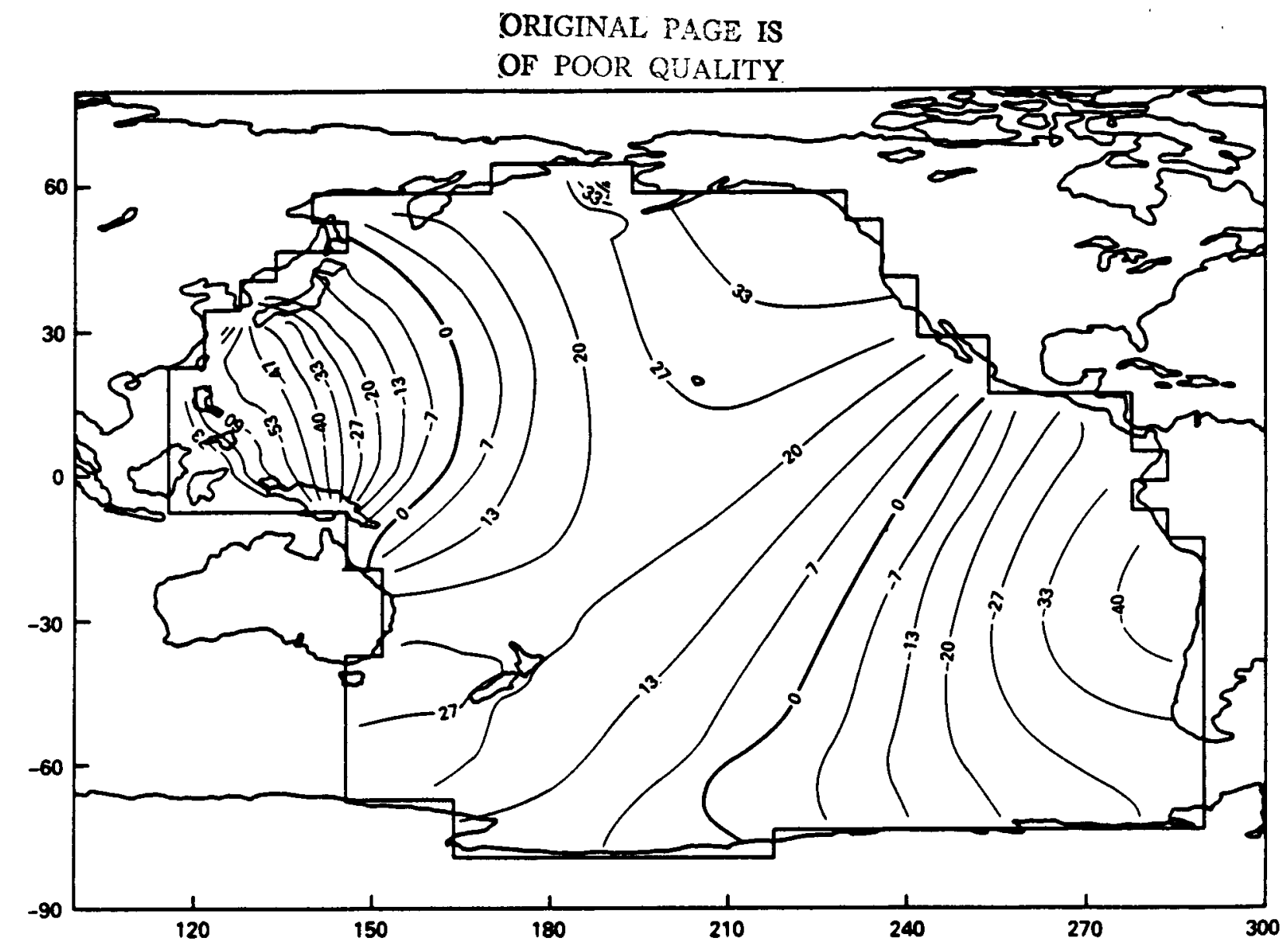

Figure 2a. Proudman function with period $=26.37$ hours. Contours of equal amplitude normalized to maximum value $=100$.

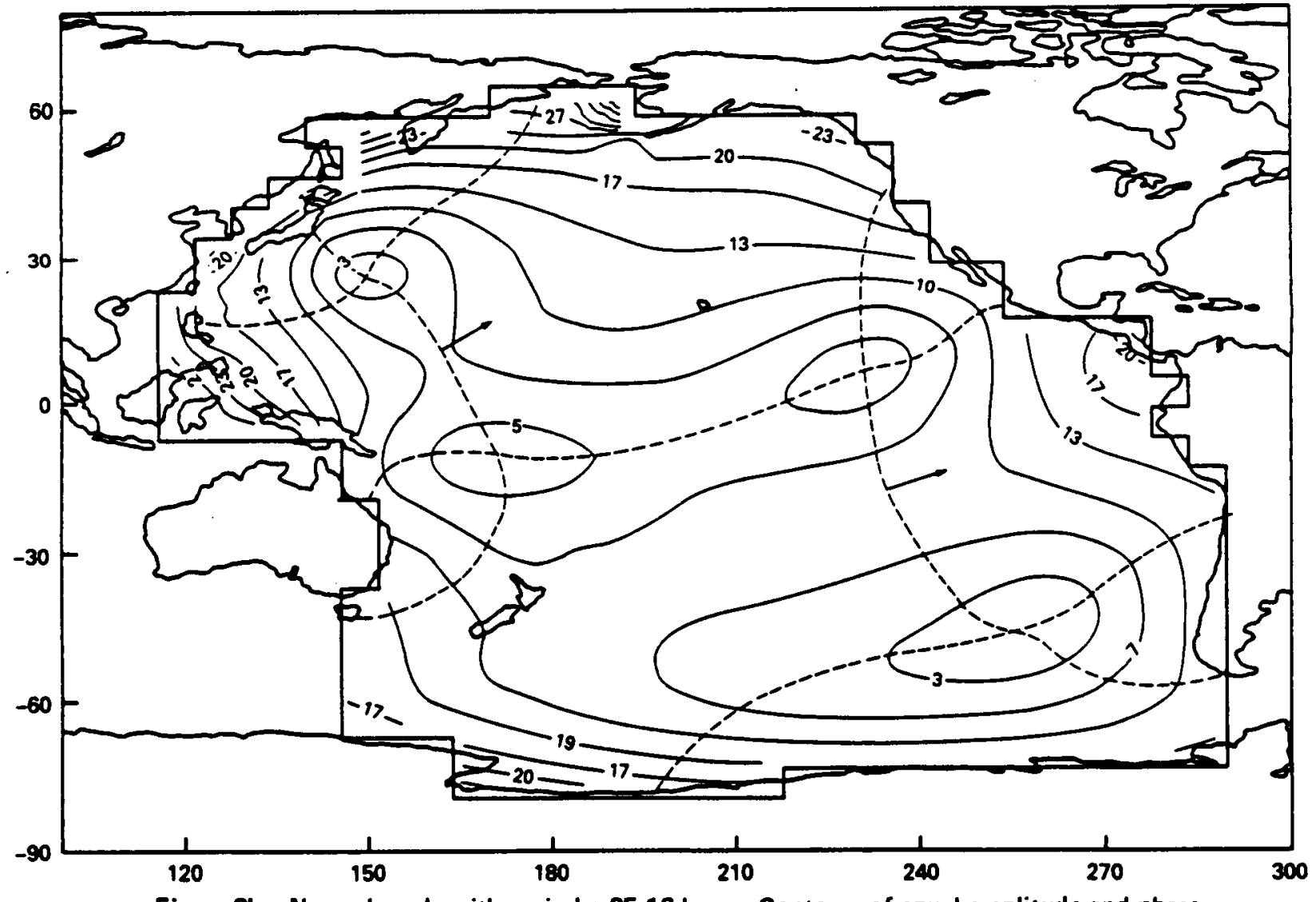

Figure 2b. Normal mode with period $=25.16$ hours. Contours of equal amplitude and phase. 


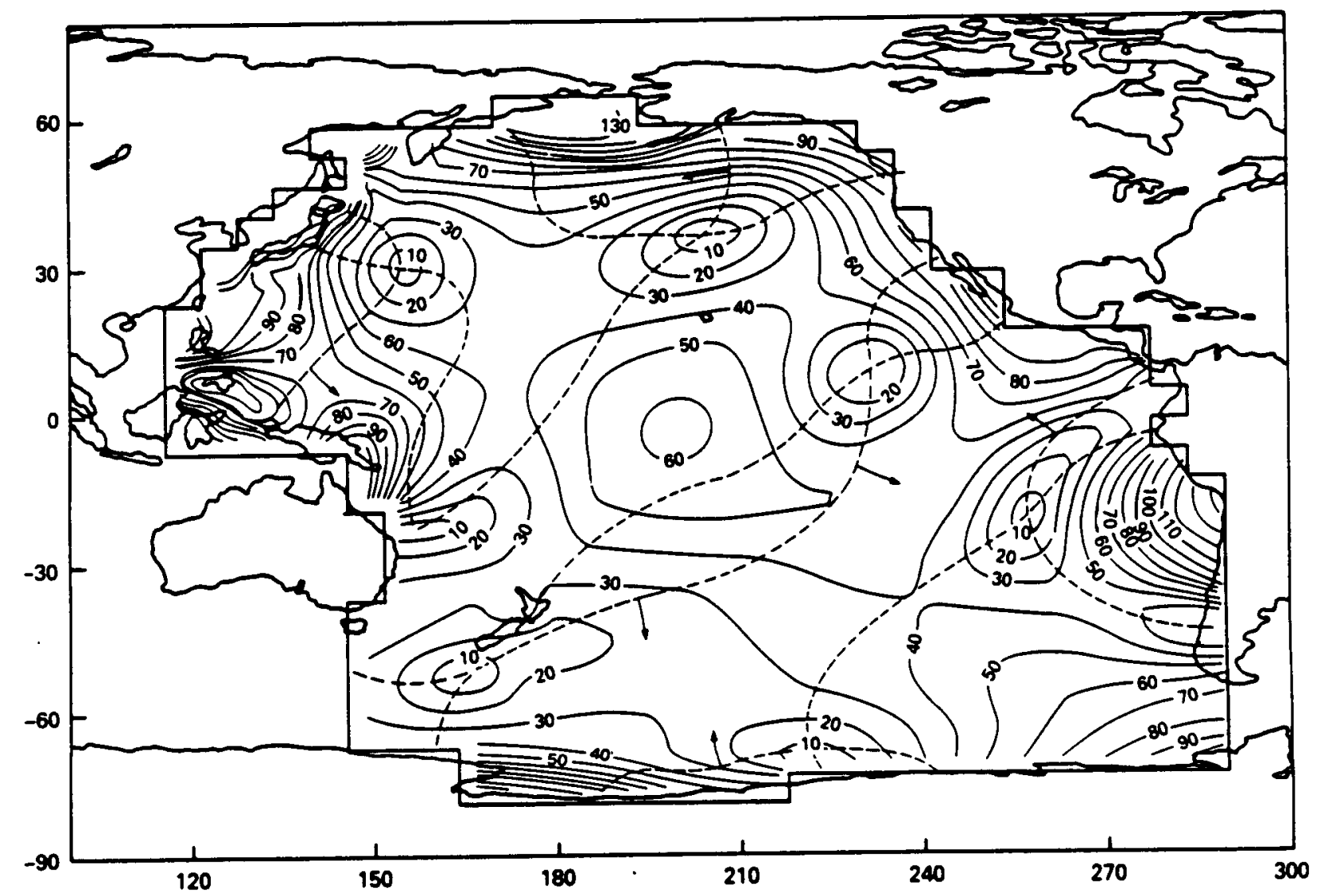

Figure 3. $M_{2}$ theoretical solution obtained from the lowest 150 modes. Contours of equal amplitude (cm) and phase.

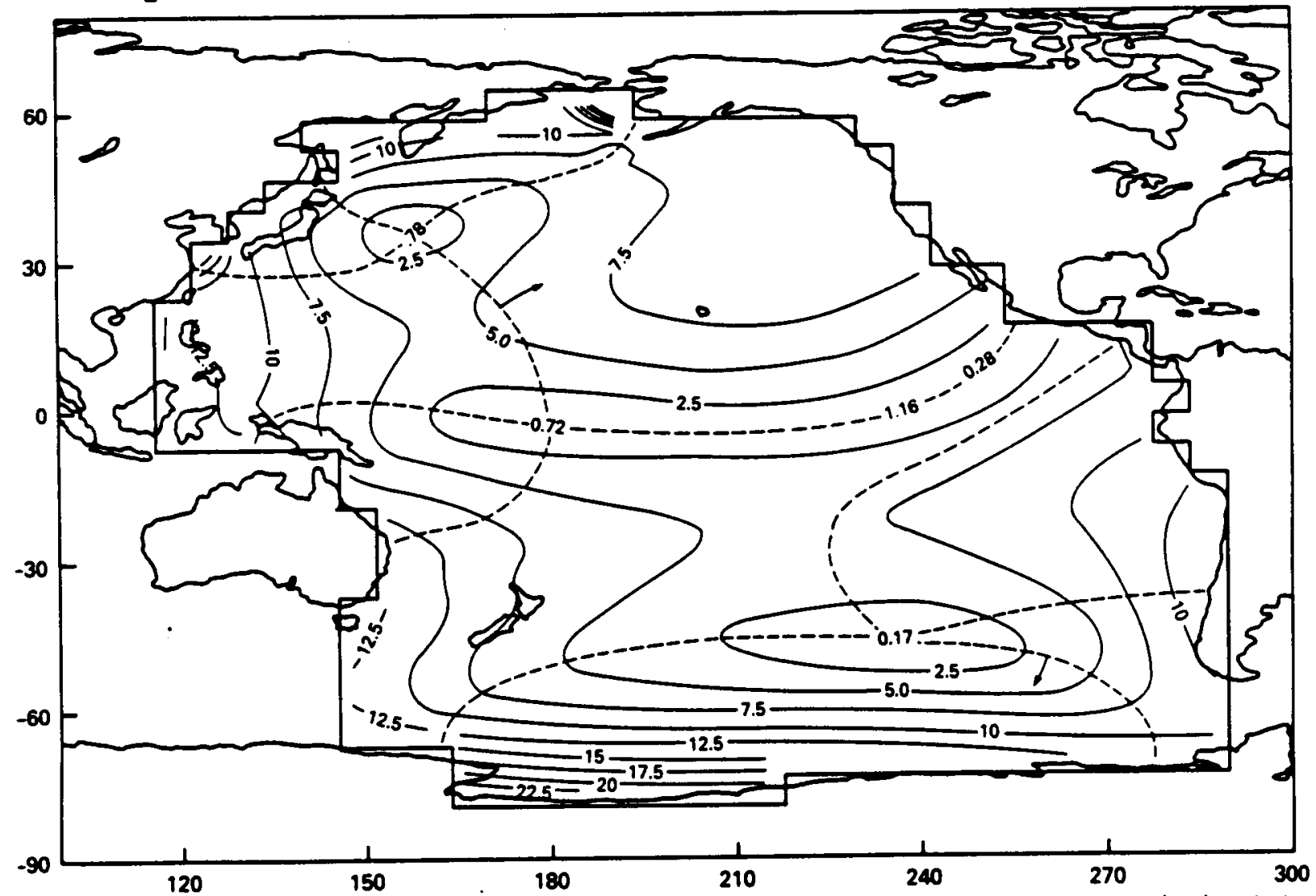

Figure 4. $0_{1}$ theoretical solution obtained from the lowest 150 modes. Contours of equal amplitude (cm) and phase. 
Table 2. Potential Energy Spectrum for the Semidiurnal Components

\begin{tabular}{|c|c|c|c|c|c|c|c|c|}
\hline \multirow[b]{2}{*}{ Rank } & \multicolumn{2}{|c|}{$\mathbf{M}_{2}$} & \multicolumn{2}{|c|}{$S_{2}$} & \multicolumn{2}{|c|}{$\mathrm{N}_{2}$} & \multicolumn{2}{|l|}{$\mathrm{K}_{2}$} \\
\hline & Period(hr) & P.E.(\%) & Period(hr) & P.E.(\%) & Period(hr) & P.E.(\%) & Period(hr) & P.E.(\%) \\
\hline 1 & 11.78 & 19.76 & 11.57 & 27.47 & 11.78 & 43.5 & 11.57 & 24.18 \\
\hline 2 & 12.26 & 17.34 & 11.28 & 19.38 & 13.77 & 12.03 & 11.28 & 17.34 \\
\hline 3 & 11.57 & 14.33 & 10.84 & 13.04 & 11.28 & 9.15 & 12.60 & 15.45 \\
\hline 4 & 11.28 & 11.93 & 12.60 & 12.11 & 9.38 & 9.11 & 10.84 & 12.05 \\
\hline 5 & 13.77 & 5.47 & 12.26 & 7.32 & 12.60 & 4.64 & 12.26 & 9.14 \\
\hline 6 & 10.61 & 4.86 & 11.78 & 3.06 & 16.12 & 4.11 & 11.78 & 3.83 \\
\hline 7 & 15.00 & 4.86 & 10.61 & 3.05 & .9 .10 & 2.07 & 8.79 & 2.55 \\
\hline 8 & 10.24 & 2.63 & 8.79 & 2.71 & 10.84 & 1.75 & 10.61 & 2.52 \\
\hline 9 & 10.84 & 1.80 & 9.38 & 2.09 & 10.61 & 1.71 & 9.38 & 1.78 \\
\hline 10 & 16.12 & 1.78 & 8.99 & 1.11 & 8.99 & 1.45 & 13.77 & 1.56 \\
\hline
\end{tabular}

Table 3. Potential Energy Spectrum for the Semidiurnal Components

\begin{tabular}{ccccccccc} 
& \multicolumn{3}{c}{$\mathrm{K}_{1}$} & \multicolumn{2}{c}{$\mathrm{O}_{1}$} & \multicolumn{2}{c}{$\mathrm{P}_{1}$} & $\mathrm{Q}_{1}$ \\
Rank & Period(hr) & P.E.(\%) & Period(hr) & P.E.(\%) & Period(hr) & P.E.(\%) & Period(hr) & P.E.(\%) \\
1 & 16.70 & 26.64 & 25.16 & 37.90 & 16.70 & 25.07 & 25.16 & 31.82 \\
2 & 21.61 & 20.13 & 20.76 & 11.26 & 21.61 & 21.34 & 16.70 & 15.04 \\
3 & 20.76 & 18.37 & 16.70 & 8.60 & 20.76 & 17.34 & 20.76 & 12.07 \\
4 & 16.12 & 10.36 & 18.65 & 8.03 & 16.12 & 11.06 & 18.65 & 6.52 \\
5 & 14.21 & 4.71 & 15.00 & 7.42 & 14.21 & 4.76 & 15.00 & 5.96 \\
6 & 13.77 & 3.26 & 12.60 & 4.79 & 43.94 & 3.14 & 13.77 & 5.50 \\
7 & 12.26 & 3.20 & 13.77 & 3.79 & 12.26 & 3.07 & 12.60 & 5.22 \\
8 & 43.94 & 2.62 & 21.61 & 3.08 & 13.77 & 3.04 & 12.26 & 4.81 \\
9 & 18.65 & 1.89 & 12.26 & 2.65 & 25.16 & 2.20 & 43.94 & 3.39 \\
10 & 25.16 & 1.51 & 43.94 & 2.19 & 18.65 & 1.61 & 14.21 & 2.89
\end{tabular}

of 11.57 hours. The energy percentages given in the table are relative to the total ( 100 percent) contributed by the 150 modes in the solution. For the diumal components, the most important modes are the ones with periods of 16.70 hours $\left(K_{1}\right.$ and $\left.P_{1}\right)$, and 25.16 hours $\left(O_{1}\right.$ and $\left.Q_{1}\right)$. The rms amplitudes computed for the various components are as follows: $\mathrm{M}_{2}(63.9 \mathrm{~cm}), \mathrm{N}_{2}(25.2 \mathrm{~cm}), \mathrm{S}_{2}(24.2 \mathrm{~cm}), \mathrm{K}_{2}(6.9 \mathrm{~cm}), \mathrm{K}_{1}(10.9 \mathrm{~cm})$, $\mathrm{P}_{1}(3.6 \mathrm{~cm}), 0_{1}(8.3 \mathrm{~cm}), \mathrm{Q}_{1}(1.1 \mathrm{~cm})$. 


\section{FITTING SCHWIDERSKI'S NUMERICAL SOLUTIONS}

Schwiderski's numerical solutions to Laplace's tidal equations, constrained to fit all the measured coastal data (Schwiderski et seq., 1983) provide a way of testing the efficiency of the Proudman function representation, vis-a-vis a spherical harmonic expansion approach. Schwiderski's amplitudes and phases for the various components have been used as data at the 510 velocity potential points of the grid. Figures $5 \mathrm{a}$ and $5 \mathrm{~b}$ show Schwiderski's solutions for the $\mathrm{M}_{2}$ and $0_{1}$ tidal components. The tidal fields were then fit by least squares, first in terms of Proudman functions, then in terms of spherical harmonics. It is expected that the Proudman functions will yield better results when fitting diurnal and semidiurnal components which have periods in the range spanned by the gravitational modes. However, the expected outcome is not as clear when fitting tidal components with long periods. In that context, the lunar fortnightly $\left(\mathrm{M}_{\mathrm{f}}\right)$, the lunar monthly $\left(\mathrm{M}_{\mathrm{m}}\right)$, and the solar semiannual $\left(\mathrm{S}_{\mathrm{sa}}\right)$ have been included in the tests. The results are given in Table 4. The second column lists the rms for the amplitude of the various numerical solutions; the third and fourth columns give the results of the fits. The $\mathrm{ms}$ of fit in the last two columns of Table 4 is defined as follows:

$$
\mathrm{rms}=\left[\sum_{\mathrm{i}=1}^{510}\left(\mathrm{AE}_{\mathrm{i}}-\mathrm{AS}_{\mathrm{i}}\right)^{2} / 510\right]^{1 / 2}
$$

where $A E_{i}$ denotes the amplitude of the estimated solution at point $i$, and $A S_{i}$ stands for the amplitude from Schwiderski's solution. As expected, the Proudman functions perform better (i.e., smaller rms) for the diumal and semidiurnal components; the $\mathrm{M}_{2}$ component can be estimated better with 150 Proudman functions than with a 14th degree spherical harmonic expansion involving 1.5 times the number of coefficients. The fortnightly and lunar monthly were estimated about equally by both methods, but the spherical harmonics give better results for the estimation of the solar semiannual component. In this last case, a 9 th degree expansion (200 coefficients) yields better results than the fit using 450 Proudman functions.

The potential energy spectra corresponding to the fits in Table 4 are partially given in Table 5 for the $\mathrm{M}_{2}$ and $0_{1}$ components, for the cases in which 150 Proudman functions were used. Comparing those with the results given in Tables 2 and 3 for the theoretical solutions, one sees some similarities and some differences. Seven out of the first ten modes, and two out of the first five, are common to both $M_{2}$ fits. In the case of $\mathrm{O}_{1}$, eight out of the first ten, and three out of the first five, are common to both fits. Figures $6 \mathrm{a}$ and $6 \mathrm{~b}$ show the solutions for $\mathrm{M}_{2}$ and $\mathrm{O}_{1}$ when fitting Schwiderski's solutions with 200 Proudman functions. Schwiderski's numerical solutions were also fitted using a reduced data set, consisting of 362 points covering the central part of the Pacific Ocean (Figure 9a). These are the points used to analyze the SEASAT altimetry data as explained in the next sections. Schwiderski's $\mathbf{M}_{2}$ tidal map was fitted using the first 90 Proudman functions (in order of decreasing space scale and length of period); an $\mathrm{ms}$ of fit (over the 362 data points) equal to $3.10 \mathrm{~cm}$ was obtained. Schwiderski's $0_{1}$ map was fitted using the first 50 Proudman functions; the $\mathrm{rms}$ of fit obtained is equal to $0.6 \mathrm{~cm}$. The coefficients derived from the fits above were used to compute the potential energy spectrum, and the results are given in Table 6 . The potential energy percentages are based on a 100 percent total using 90 modes for $M_{2}$ and 50 modes for $0_{1}$. For comparison, the $M_{2}$ and $0_{1}$ theoretical solutions obtained by using 150 modes were also fitted. The corresponding rms of fit were 0.57 $\mathrm{cm}$ for $\mathrm{M}_{2}$ (using 90 functions) and 0.17 for $0_{1}$ (using 50 functions); both over the 362-point data set. The corresponding potential energy spectra are also given in Table 6 . The first thing to notice in these results is the preponderance of one mode in all cases-the mode with a rotational period of 21.61 hours. The corresponding Proudman function has a nonrotational period of 22.11 hours. This mode is especially important when fitting the $0_{1}$ component; it then accounts for more than 50 percent of the potential energy. In general, the fits to Schwiderski's solutions and to the theoretical solutions show similar patterns in the potential energy spectrum aithough they are not identical. Six out of the first ten, and three out of the first five, are common in the fits to $\mathrm{M}_{2}$; seven out of the first ten are common in the $0_{1}$ fits. Also, the first three are common, and in the same order, in the fits to $0_{1}$. 
Table 4. Fitting Schwiderski's Numerical Solutions Using Proudman Functions and Spherical Harmonics. RMS Values in $\mathrm{cm}$.

$\begin{array}{cccc}\begin{array}{c}\text { Tidal } \\ \text { Component }\end{array} & \begin{array}{c}\text { RMS Amplitude, } \\ \text { Schwiderski }\end{array} & \begin{array}{c}\text { Proudman functions } \\ \text { RMS of Fit (no. } \\ \text { of functions) }\end{array} & \begin{array}{c}\text { Spherical Harmonics } \\ \text { RMS of Fit (degree } \\ \text { of expansion) }\end{array} \\ \mathrm{M}_{2} & 33.82 & \begin{array}{l}4.40(150) \\ 3.54(200) \\ 1.03(450)\end{array} & \begin{array}{l}8.81(9 \mathrm{th}) \\ 5.56(14 \mathrm{th})\end{array} \\ \mathrm{S}_{2} & 11.67 & 1.29(200) & 2.98(9 \mathrm{th}) \\ \mathrm{K}_{1} & 17.16 & 0.66(450) & 1.62(14 \mathrm{th}) \\ 0_{1} & 12.19 & 2.48(200) & 4.40(9 \mathrm{th}) \\ & & 1.17(450) & 2.91(14 \mathrm{th}) \\ \mathrm{M}_{\mathrm{f}} & & 2.01(150) & 3.17(9 \mathrm{th}) \\ & 1.21 & 1.74(200) & 2.14(14 \mathrm{th}) \\ \mathrm{M}_{\mathrm{m}} & & 0.71(450) & 0.22(9 \mathrm{th}) \\ & 0.90 & 0.18(200) & 0.15(14 \mathrm{th}) \\ \mathrm{S}_{\mathrm{sa}} & & 0.13(450) & 0.21(9 \mathrm{th}) \\ & 1.52 & 0.13(200) & 0.14(14 \mathrm{th}) \\ & & 0.05(450) & 0.30(9 \mathrm{th}) \\ & & 0.43(200) & 0.17(14 \mathrm{th})\end{array}$

Table 5. Potential Energy Spectrum for Schwiderski's $M_{2}$ and $O_{1}$ Using Fits to 510 Points

\begin{tabular}{|c|c|c|c|c|}
\hline Rank & Period (hr) & P.E. (\%) & Period (hr) & P.E. $(\%)$ \\
\hline 1 & 11.57 & 22.10 & 18.65 & 17.90 \\
\hline 2 & 12.26 & 12.87 & 25.16 & 15.66 \\
\hline 3 & 12.60 & 6.08 & 16.70 & 13.73 \\
\hline 4 & 10.84 & 4.45 & 13.77 & 8.29 \\
\hline 5 & 10.61 & 4.26 & 32.82 & 7.27 \\
\hline 6 & 15.00 & 4.08 & 16.12 & 5.73 \\
\hline 7 & 16.70 & 4.03 & 12.26 & 3.61 \\
\hline 8 & 11.78 & 2.53 & 43.94 & 2.74 \\
\hline 9 & 15.33 & 2.42 & 12.60 & 2.68 \\
\hline 10 & 11.28 & 2.20 & 21.61 & 2.47 \\
\hline
\end{tabular}




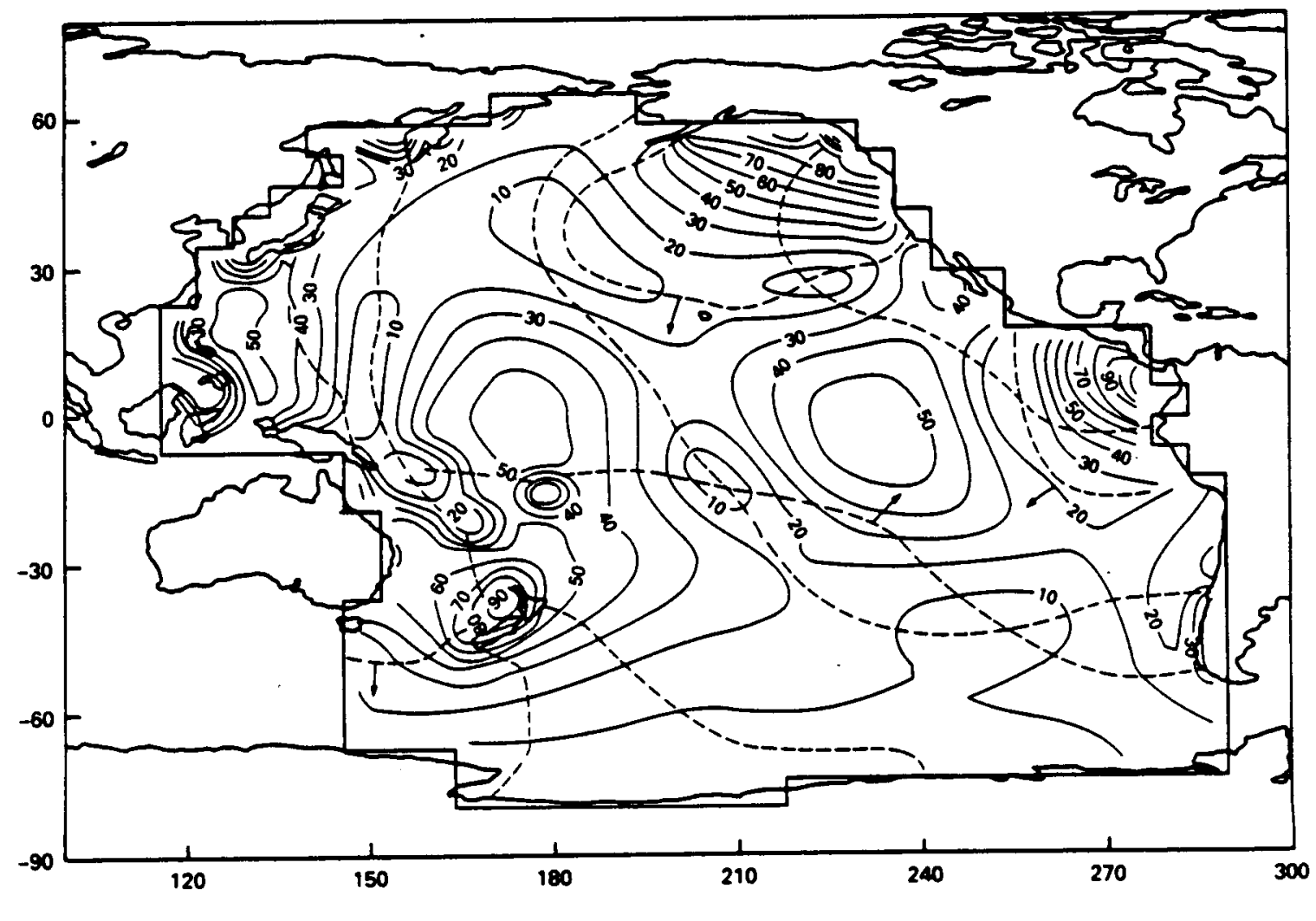

Figure 5a. Contours of amplitude (solid lines, centimeters) and Greenwich phase lag at $90^{\circ}$ intervals (broken lines) from Schwiderski's (1983) global model of the $M_{2}$ tide constrained by coastal tide-gauge data. Arrows, attached to $0^{\circ}$ phase contours, indicate the sense of phase progression around amphidromes.

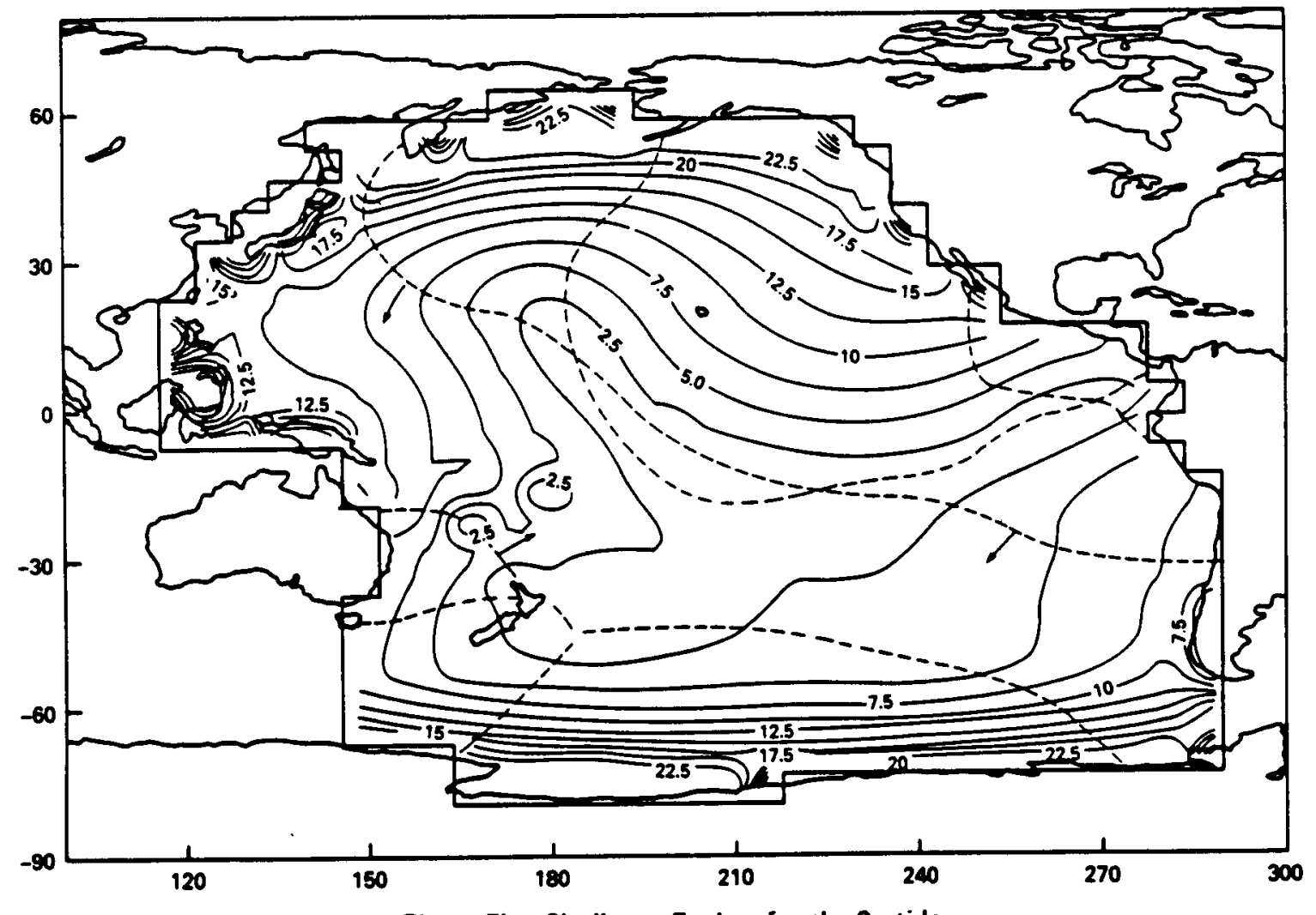

Figure $5 \mathrm{~b}$. Similar to $5 \mathrm{a}$, but for the $0_{1}$ tide. 


\section{ORGNAT PAOS IS \\ OF POOK QUALITY}

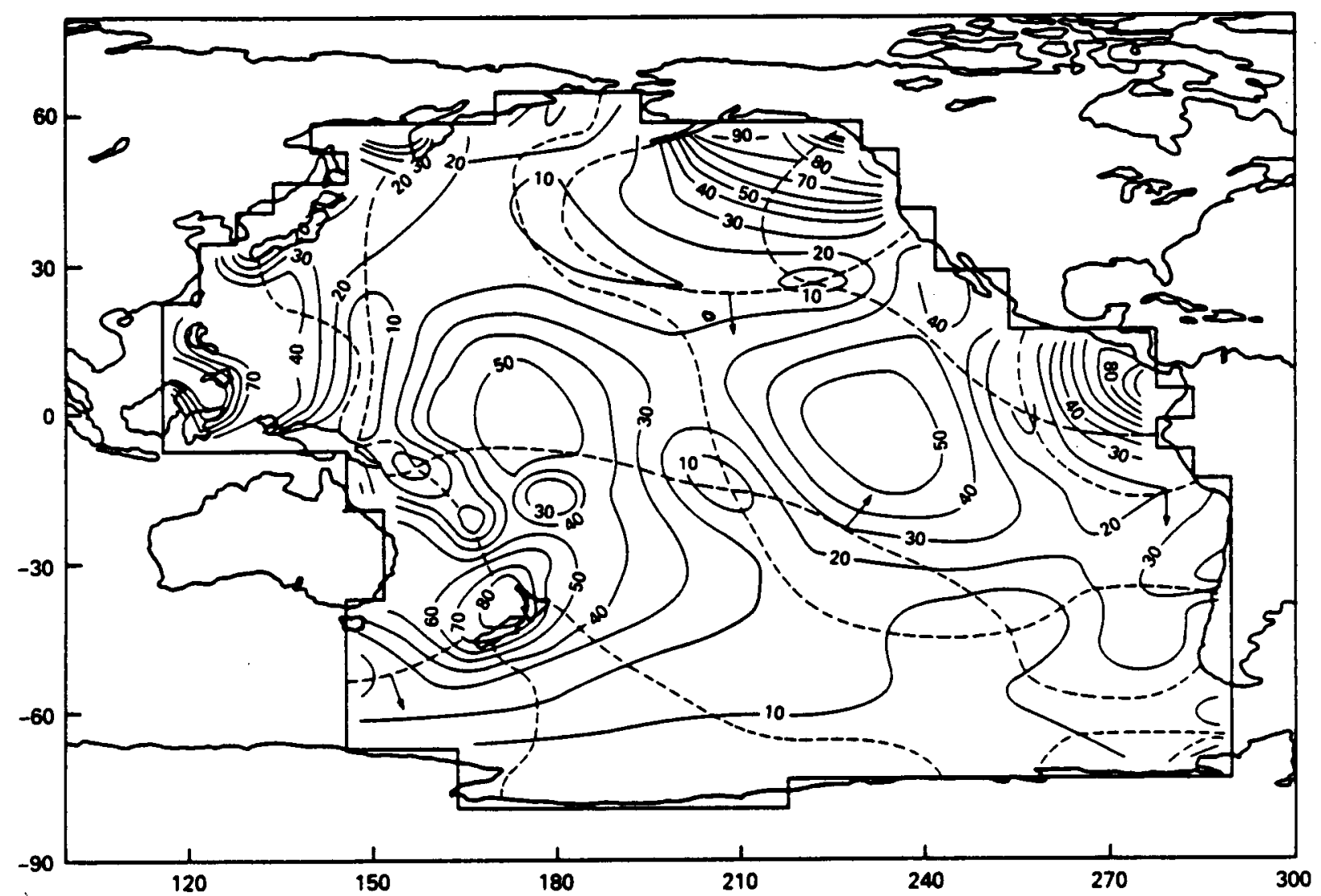

Figure 6a. A synthesis of 200 Proudman functions with coefficients computed for least-squares fit to $M_{2}$ data corresponding to 5 a. Notation as in Figure 5 a.

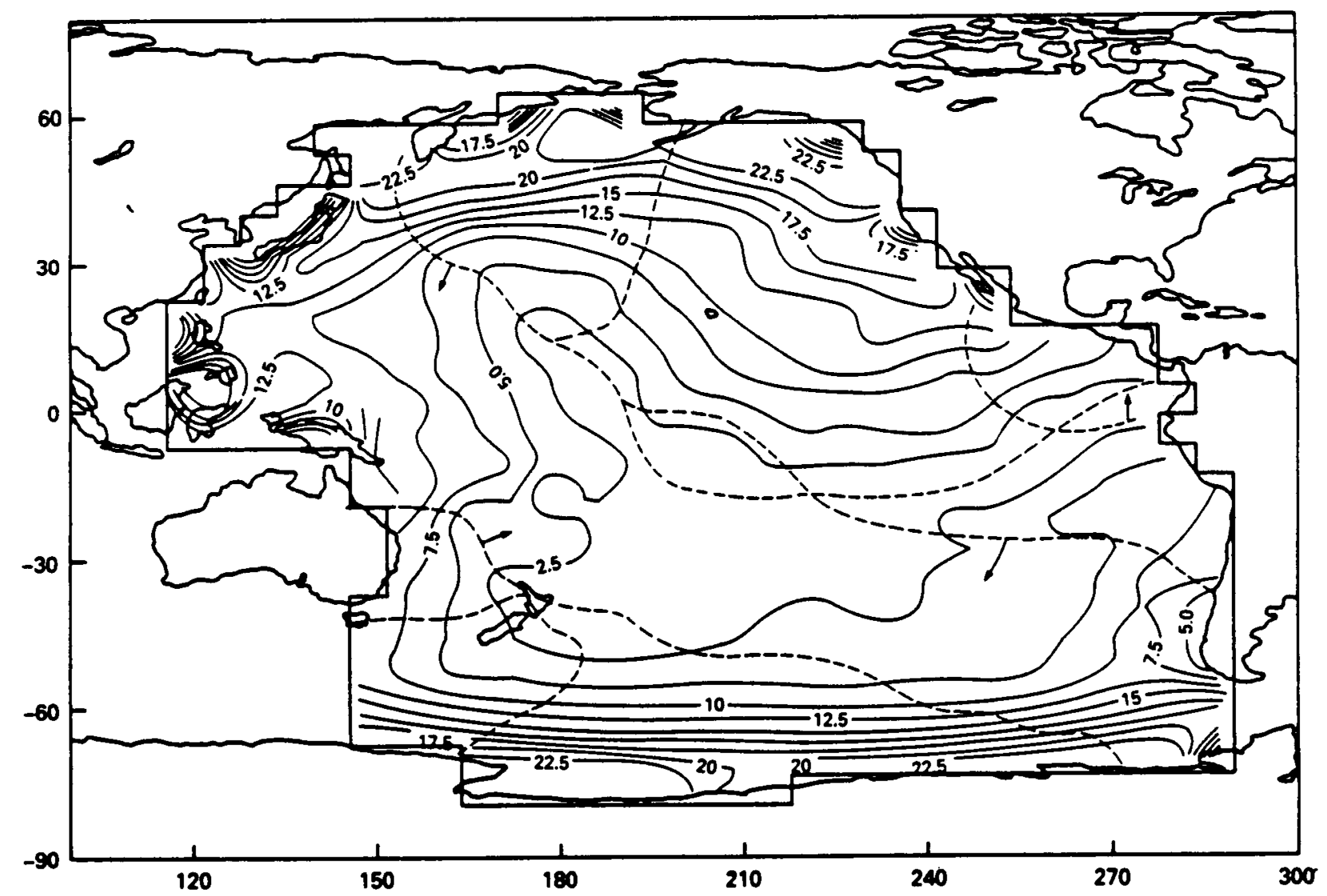

Figure $6 \mathrm{~b}$. Similar to $6 \mathrm{a}$, but for $0_{1}$ data as mapped in Figure $5 \mathrm{~b}$. 
Table 6. Potential Energy Spectrum for $M_{2}$ and $O_{1}$ Using Fits to 362 Data Points

\begin{tabular}{rrrrrrrrrr} 
& \multicolumn{2}{c}{$\mathbf{M}_{2}($ Schwiderski) } & \multicolumn{2}{c}{$\mathbf{M}_{2}$ (theoretical) } & \multicolumn{2}{c}{$0_{1}$ (Schwiderski) } & \multicolumn{2}{c}{$0_{1}$ (theoretical) } \\
Rank & Period(hr) & P.E.(\%) & Period(hr) & P.E.(\%) & Period(hr) & P.E.(\%) & Period(hr) & P.E.(\%) \\
& & & & & & & & & \\
1 & 21.61 & 15.56 & 21.61 & 19.35 & 21.61 & 56.76 & 21.61 & 57.77 \\
2 & 9.95 & 11.36 & 20.76 & 14.60 & 20.76 & 20.75 & 20.76 & 18.80 \\
3 & 11.78 & 10.22 & 9.95 & 8.98 & 25.16 & 3.43 & 25.16 & 9.57 \\
4 & 14.21 & 8.24 & 11.78 & 6.54 & 16.70 & 2.76 & 18.65 & 3.69 \\
5 & 9.33 & 5.47 & 18.65 & 4.45 & 12.60 & 2.24 & 16.12 & 1.70 \\
6 & 10.61 & 4.58 & 12.60 & 3.95 & 32.82 & 1.87 & 32.82 & 0.97 \\
7 & 25.16 & 4.56 & 10.84 & 3.71 & 18.65 & 1.58 & 15.00 & 0.87 \\
8 & 8.66 & 3.59 & 13.77 & 3.39 & 10.61 & 1.52 & 15.33 & 0.64 \\
9 & 20.76 & 3.52 & 10.61 & 3.07 & 9.10 & 1.02 & 11.28 & 0.57 \\
10 & 10.24 & 2.89 & 14.21 & 2.70 & 11.28 & 0.97 & 10.61 & 0.55
\end{tabular}

\section{TIDAL ANALYSIS OF SEASAT ALTIMETRY}

Expansion in terms of a proper set of spatial basis functions is, in principle, the best way of extracting the tidal field from sea surface topography measured by a satellite altimeter. Attempts have been made to define the $\mathrm{M}_{2}$ tide in the global ocean by analysis of the altimetry from SEASAT using expansions of spherical harmonics (Mazzega, 1985) and of computed normal modes (Woodworth and Cartwright, 1986), both with some degree of success and with some limitations. The limitation of spherical harmonics is that, since data noise severely limits the order of expansion, it cannot properly model the finer tidal structure near the edges of the ocean basins, nor the abrupt transition from one ocean basin to another across a narrow landmass (e.g., Central America). Computed normal modes of oscillation correctly model the requirements of ocean basin geometry, but are limited by the physical approximations (e.g., lack of friction) built into their formulation. Both Mazzega (1985) and Woodworth and Cartwright (1986) achieved better results by separating the solutions for different ocean basins at the expense of discontinuity across their common boundaries.

The set of Proudman functions for the Pacific Ocean described in the first sections of this paper should provide a better alternative to both spherical harmonics and normal modes, because they embody the correct requirements of mass conservation and boundary flow without imposing any artificial dynamic constraints in their formulation. An expansion of the tidal field in Proudman functions may, therefore, embody any reasonable regime of linear intemal dissipation, which is important in tidal theory. The principal limitation is the implied lack of energy transmission across the model boundaries, but this is not considered to be very great in the seas bordering the Pacific Ocean. [The Bering Sea, at one time considered to be a major sink of $M_{2}$ tidal energy, has since been shown to be insignificant in this respect (Sundermann, 1977)].

In applying Proudman functions to analyze SEASAT altimetry, we restricted the analyisis to an interior zone of the Pacific (Figures 9a, b) which covers about three-quarters of the total area used for computing the functions, in order not to confuse the fitting by fine tidal structure near the coastal boundaries. In particular, the difficult tidal area around New Zealand has been excluded, as well as regions of high mesoscale activity in the Kuroshio Current off Japan and at high southern latitudes, (Cheney, Marsh and Beckley, 1983). The loss of ideal orthogonality of the set of functions over the smaller area is not too serious, and in any case, the area of integration is weighted by the disposition of valid data along the satellite's groundtracks. The use of nonzero cross-products between members of the set is a normal part of the analysis procedure:

\section{The Altimeter Data Set}

We used a file of altimetric Sea Surface Heights (SSH) and related data specially prepared from the original GDR tapes by Oscar L. Colombo of EG\&G for purposes such as tidal analysis. All data were taken 
from the '3-day repeat' phase of the SEASAT mission (1978, Sept. 13 - Oct. 10), here reduced to the period Sept. 15 - Oct. 9, as far as roughly-continuous data series are concerned, apart from some gaps of a few hours. The pattern of ground-tracks for this period, repeated every 3 days, with a minimum separation of $8.4^{\circ}$ in longitude between parallel tracks, has been reproduced many times; see, for example, Figure 4 of Brown and Hutchinson (1981).

The original $1 \mathrm{~s}^{-1}$ data had been smoothed by Colombo to roughly 10 s intervals corresponding to about $70 \mathrm{~km}$ of ground-track, and adjusted to a pre-set grid of earth-positions. The altimeter heights along tracks which, owing to a slight drift in the orbit, did not quite pass over the pre-set positions, were corrected by an adjustment in height proportional to the cross-track slope of the geoid in the region concerned. All data which, for a variety of technical reasons, showed gross departure from consecutive smoothness were eliminated from the data set.

The computed orbit used to correct the altimeter heights to SSH was the Goddard Space Flight Center's PGSS4 orbit, which was more accurate than any other computations for SEASAT prior to 1987. Apart from this, a standard suite of algorithms for the correction of radar path-length had been applied to the data at an early stage of processing. These corrections included subtraction of the 'body-tide' of the earth's crust and a computed 'ocean tide' from the models of Schwiderski et seq. 1980. Since we are concerned with analysis of the ocean tide signal, we restored it by adding to the given SSH data exactly the same figures for 'ocean tide' which had previously been subtracted. The geocentric tidal signal contained in the adjusted SSH consisted, therefore, of the ocean tide relative to earth as normally recorded, slightly modified by the 'load tide', or ocean-induced deformation of the ocean floor, (Parke and Hendershott, 1980).

\section{Corrections for Geoid and Crbit Error}

The adjusted $\mathrm{SSH}$, as described above, is dominated by the geoid signal of order $\pm 50 \mathrm{~m}$ and to a lesser, but important, extent by the error in the computed orbit, of order $\pm 1 \mathrm{~m}$. These have to be subtracted by some means for oceanographic analysis. The repeated track provides the most convenient means of removing at least the geographically-invariant part of the SSH, consisting of the gooid, though somewhat distorted by the quasi-permament dynamic ocean topography. A commonly-employed method is to reduce each recorded height $\mathrm{SSH}(\theta, \lambda, t)$ at time $t$ to the anomaly

$$
\mathrm{DH}(\theta, \lambda, \mathrm{t})=\operatorname{SSH}(\theta, \lambda, \mathrm{t})-\operatorname{MSH}(\theta, \lambda)
$$

where MSH $(\theta, \lambda)$ is the mean of all recorded heights along repeated tracks over the position with latitude $\theta$, longitude $\lambda$. This is a good method in principle when applied to a very long record, but in the case of SEASAT, with $\leqslant 8$ repeated passes over each section of track, frequent irregular fallout of some data values introduces noise in MSH, owing to the irregular distribution of orbit errors among the eight possible passes. Such noise largely accounts for the irregularity of the histograms of anomalies shown in Figure 6 of Woodworth and Cartwright (1986).

We have avoided such irregularity in the present study by working in terms of the 'running difference'

$$
\Delta H(\theta, \lambda, t)=\operatorname{SSH}(\theta, \lambda, t)-\operatorname{SSH}(\theta, \lambda, t+K T)
$$

where $T$ closely approximates the mean repeat period, 3.0089 days in the case of SEASAT (the exact value being determined by exact repeatability of $\theta, \lambda$ ), and $K$ is an arbitrary small integer. In fact. $K$ was set equal to 2 , because the time difference of $2 \mathrm{~T}$ conveniently matches the $6 \mathrm{~d}$ duration of the consecutive arclengths used for computation of the PGSS4 orbit. Whenever either of the two variables on the right of (4.2) was missing or invalidated, the corresponding value of $\Delta \mathrm{H}$ was omitted from subsequent analysis.

$\Delta \mathrm{H}$, as defined by (4.2), may not be a useful variable for more general oceanographic analysis, but it is well suited to tidal analysis. Omitting $(\theta, \lambda)$ for brevity, a harmonic tidal component

$$
\operatorname{SSH}(t)=H \cos \omega t
$$


appears in $\Delta \mathrm{H}$ as $\mathrm{fH} \cos (\omega \mathrm{t}-\phi)$, where

$$
\mathrm{f}=2 \sin (\omega \mathrm{KT}) / 2, \phi=(\pi-\omega \mathrm{KT}) / 2
$$

Values of $f$ and $\phi$ for six leading harmonic tidal constituents, with $K=1$, and 2 and $T$ equal to the SEASAT repeat period, are listed in Table 7 . The lunar constituents $Q_{1}, 0_{1}, N_{2}$, and $M_{2}$ are enhanced in amplitude, while the solar constituents $K_{1}$ and $S_{2}$, being aliased into very low frequencies by the near-sun synchronism of the orbit, are conveniently suppressed. The corresponding lunar harmonic constituents in SSH(t) are, therefore, easily recovered from their values in $\Delta \mathrm{H}(\mathrm{t})$ by applying well-defined adjustments to amplitude and phase.

We still have to consider the removal of error in the computed satellite orbit, which in the case of $\Delta \mathrm{H}$ with $\mathrm{K}=2$ is, in effect, the difference in orbit error between two consecutive $6 \mathrm{~d}$ arcs. Orbit error is known to have very long spatial scales, and the usual approach to limited areas of ocean is to subtract an arbitrary 'bias and tilt' from each pass, calculated to minimize $\mathrm{DH}(t)$ or some set of crossover differences. Such methods are not appropriate to the analysis of long wavelength oceanic phenomena over large ocean basins, because some of the signal will be eliminated as part of the bias and tilt. (Woodworth and Cartwright (1980) describe methods of tidal analysis in which the small-scale tilt of DH is itself taken as the variable, thus partially removing the problem of bias.) We have tried a new approach in which a nearly sinusoidal form.

$$
E(t)=A(t) \cos \Omega t+B(t) \sin \Omega t+C(t)
$$

is optimally fitted to the variable

$$
\Delta_{0} H(t)=\Delta H(t)-\Delta H^{\prime}(t)
$$

where A, B, C, are slowly ranging arbitrary functions of time, $\Omega=86 \pi / \mathrm{T}$, the 'orbital frequency' for SEA$\mathrm{SAT}$. and $\Delta \mathrm{H}^{\prime}$ is the difference in (Schwiderski) model ocean tide corresponding to (4.2).

It is well known that a large part of the orbit error is spectrally concentrated near the once-per-revolution frequency $\Omega$, but theoretical studies have shown that the spectrum is not an infinitesimally narrow line which would imply constant values of A, B, C for any arc or for each of a pair of arcs. It has also been suggested that $A, B$, and $C$ could be represented with low-degree polynomials over ephemeris arcs up to 7 days long; Colombo (1984) has proposed using quadrics for A and B and somewhat higher-degree curves for $C$. We have compromised by evaluating the mean values of $A, B, C$, over all valid global data $\Delta_{0} H$ during sequences of three consecutive orbits; the origin of $t$ taken centrally at an ascending equatorial crossing, and least-squares covariance matrices weighted by a cosine-taper window. A typical set of sequences of such values, evaluated with central origins at every consecutive orbit during the 6-day arc commencing 1978 Sept. 17.0, is shown in Figure 7a.

There is jitter in each sequence of coefficients, owing to the irregular sampling of ocean track along each orbit, to the spasmodic fallout of data, and to areas of residual tide from inaccurate $\Delta \mathrm{H}^{\prime}$; but distinct secular trends are obvious, justifying the general form (4.4). For definition of the orbit error $E(t)$ to be subtracted from every sample of $\Delta H(t), A, B, C$ were approximated by smooth polynomials up to the 4 th order as depicted in Figure $7 \mathrm{~b}$. The curves are clearly not linear, and the amplitude $\left(\mathrm{A}^{2}+\mathrm{B}^{2}\right)^{1 / 2}$ depicted by a continuous line never reaches zero, but varies between about 0.5 and 1.0 meters. These figures accord with simple observations of cross-over differences in SSH from the PGSS4 orbit.

Typical variances of the global data for $\Delta_{0} H(t)$, before and after subtraction of $E(t)$ from (4.4), are 0.142 and $0.051 \mathrm{~m}^{2}$ respectively, both figures being averages over the same several samples. Note that the second, i.e., residual, variance is expected to be about twice the intrinsic variance of the sea surface (tidereduced) because of the definition of $\Delta \mathrm{H}$ (4.2). Within our interior Pacific area, the corresponding figures from 19,351 values of $\Delta_{0} \mathrm{H}(\mathrm{t})$ were 0.039 and $0.008 \mathrm{~m}^{2}$, respectively. These figures compare satisfactorily with the typical $\mathrm{ms}$ residual sea surface, about $0.07 \mathrm{~m}$, deduced for the same area from the map of Cheney 


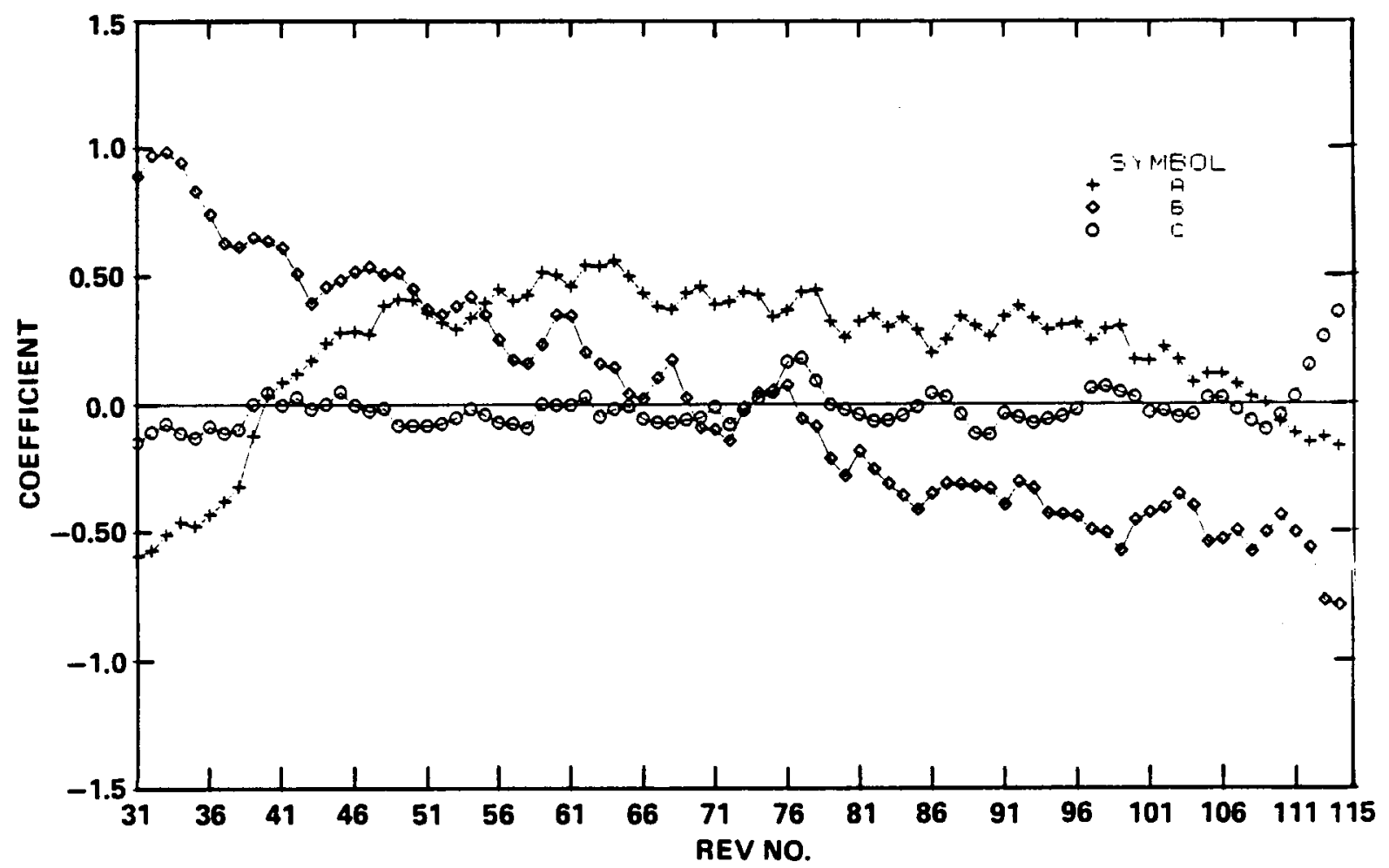

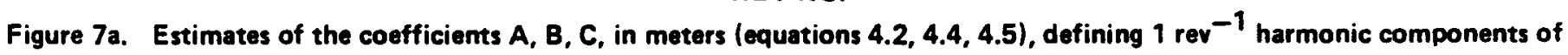
tide-reduced differenced sea surface topography derived from SEASAT, reflecting the principal component of the orbit error. Individual points are evaluated at the ascending node of each revolution by summation over 3 consecutive revolutions. Revolution numbers (abscissa) are arbitrary, with 31 corresponding to 1978 Sep. 17, $2.079 \mathrm{~h}$.

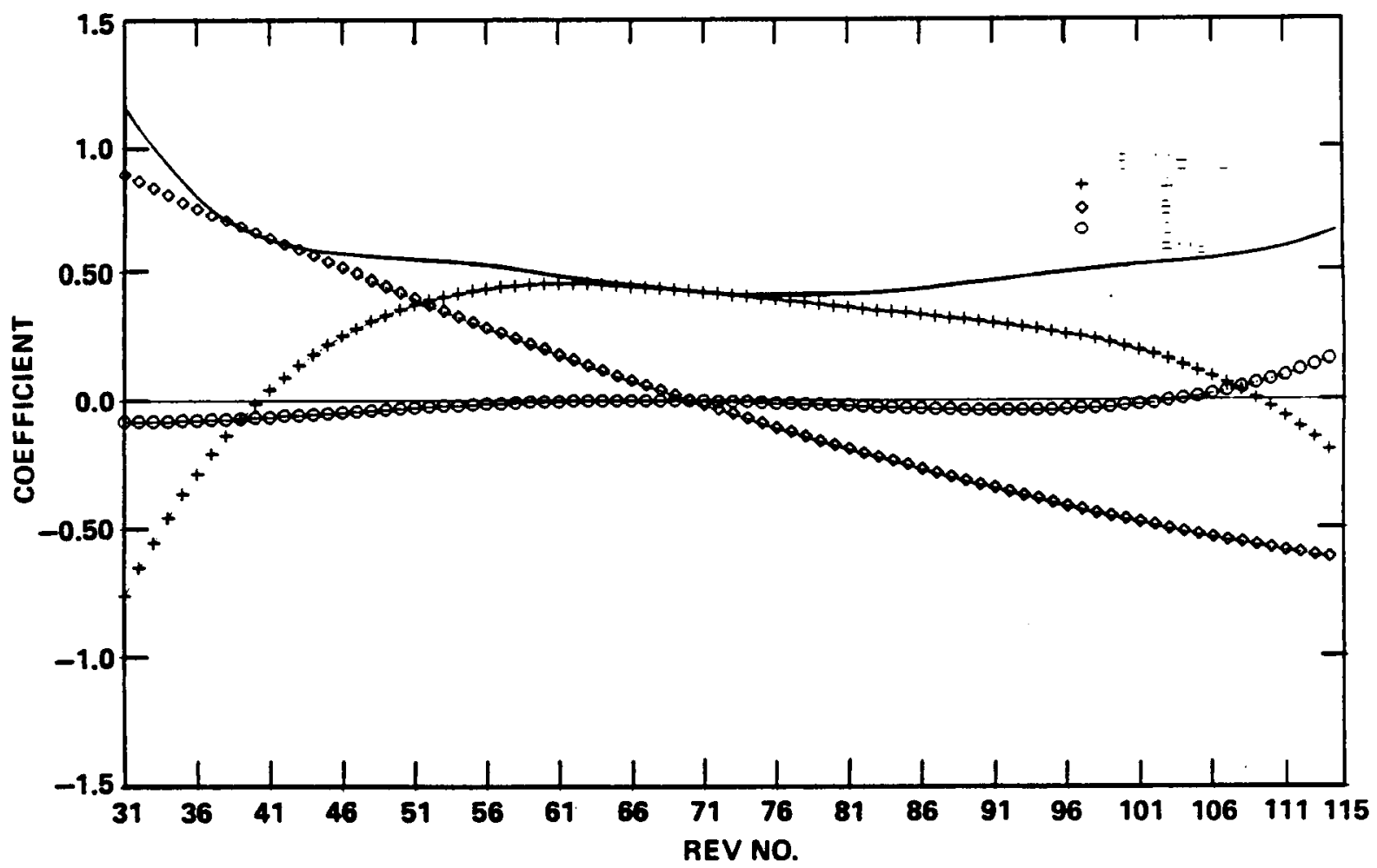

Figure 7b. Low-order polynomial splines fit to the harmonic $1 \mathrm{rev}^{-1}$ coefficients plotted in Figure 7a. The line labelled rms is the corresponding harmonic amplitude $\left(A^{2}+B^{2}\right)^{1 / 2}$. Notation and scale as in Figure $7 a$. 
and Marsh (1983). The variance figures for this area after restoration of the tidal signal, that is, for $\Delta H$ and for $\Delta \mathrm{H}-\mathrm{E}$, were 0.235 and $0.202 \mathrm{~m}^{2}$. The tidal signal is clearly the dominant variation in our corrected data set.

\section{Choice of Tidal Time-Harmonics}

Sampling at a time interval $\mathrm{T}$ imposed by the satellite's orbit aliases the harmonic constituents of the tide, as sampled at any particular point on the ground track, into much longer periods $T_{a}$, (see, for example, Parke and Rao, 1983). The values of $T_{a}$ in days for the dominant constituents are listed in the last column of Table 7. The duration of the repeated-track data, further reduced by effectively 6 days by the use of the variable $\Delta H(4.2)$, limits our data span available from analysis to about $17.5 \mathrm{~d}$. From Table 7 , this covers a little more than one complete cycle of $\mathrm{M}_{2}$ or $\mathrm{O}_{1}$ and a little less than two complete cycles of $\mathrm{N}_{2}$ and $Q_{1}$. Only a small fraction of a cycle of $S_{2}$ and $K_{1}$ is covered, but these and other solar constituents may be ignored due to their small $f$ factors.

One cycle of oscillation makes a rather poor sample for harmonic analysis at an individual point, but the use of spatial basis functions greatly improves the sampling efficiency by relating data along and between tracks. The spatial sequence of tracks presents additional cycles of phase change. By a similar process, the diurnal and semidiurnal tides, which have rather similar values of $T_{\mathrm{a}}$, are decoupled by including both ascending and descending tracks in the same spatial scheme. (The correction $E(t)(4.4)$ is also very relevant to the latter case).

In order not to overburden our analysis scheme with too many unknown parameters, we linked $\mathrm{N}_{2}$ and $\mathrm{M}_{2}$ as an anomalistic monthly variation of arbitrary amplitude and phase, and linked $\mathrm{Q}_{1}$ and $0_{1}$ in a similar fashion. In exact terms, instead of seeking a solution for $\mathrm{M}_{2}$ in the form

$$
\sum_{n}\left(A_{n}(\theta, \lambda) \cos \omega t+B_{n}(\theta, \lambda) \sin \omega t\right)
$$

we replace $\cos \omega t, \sin \omega t$ by

$$
c(t)=a(t) \cos \omega t+\beta(t) \sin \omega t, s(t)=a(t) \sin \omega t-\beta(t) \cos \omega t
$$

respectively, where

$$
\begin{aligned}
a(t) & =1+\epsilon \cos (\delta \mathrm{t}-\gamma) \\
\beta(t) & =\epsilon \sin (\delta \mathrm{t}-\gamma) \\
\delta & =2 \pi / 27.555 \mathrm{~d}-1 \\
\epsilon, \gamma & \text { are assigned constants. }
\end{aligned}
$$

The elliptical modulation corresponding to the 'equilibrium tide' would give $\epsilon=0.191, \gamma=0$ for both $\mathrm{N}_{2}$ relative to $\mathrm{M}_{2}$ and $\mathrm{Q}_{1}$ relative to $0_{1}$. A simple analysis of the relationships between these constituents in Schwiderski's model for the area of the Pacific Ocean gave

$$
\begin{aligned}
& \epsilon=0.20, \gamma=22^{\circ} \text { for } \mathrm{M}_{2}, \\
& \epsilon=0.21, \gamma=8^{\circ} \text { for } 0_{1},
\end{aligned}
$$

both results having coherence greater than 0.9 . We used these numerical values with $(4.6,4.7)$ in all the following analyses.

We have thus reduced the number of tidal constituents which are relevant to this data set to one semidiumal and one diurnal harmonic with independent parameters to be assigned by least-squares analysis. All previous tidal analyses of SEASAT altimetry have ignored the diurnal tides. We have retained them because the diurnal tides in the Pacific are larger than elsewhere with respect to the semidiurnal tides, and also because our procedures for removing the geoid and orbit errors are much better than in any other published exercise of this kind. 
Table 7. Magnifications and Phase Lags (Equations 4.2, 4.3)

\begin{tabular}{|c|c|c|c|c|c|c|}
\hline Darwin & $\omega / 2 \pi$ & & & & & $\mathrm{T}_{\mathrm{a}}$ \\
\hline Symbol & cycles $d^{-1}$ & f & $\phi^{\circ}$ & f & $\phi^{\circ}$ & Days \\
\hline $\mathrm{Q}_{1}$ & 0.8932 & 1.6624 & -33.78 & -1.8484 & 202.45 & 9.6 \\
\hline $0_{1}$ & 0.9295 & 1.1916 & -53.43 & -1.9140 & 163.14 & 14.8 \\
\hline $\mathrm{K}_{1}$ & 1.0027 & -0.1074 & -93.08 & 0.2144 & 83.85 & 176.4 \\
\hline $\mathrm{N}_{2}$ & 1.8960 & -1.6004 & 143.15 & -1.9197 & 196.30 & 10.1 \\
\hline $\mathrm{M}_{2}$ & 1.9323 & -1.1036 & 123.49 & -1.8408 & 156.98 & 16.4 \\
\hline $\mathrm{S}_{2}$ & 2.0000 & 0.1112 & 86.81 & 0.2221 & 83.62 & 171.1 \\
\hline
\end{tabular}

\section{Expansion in Proudman Functions}

Formally, we evaluate the set of coefficients $a_{1, n}, b_{1, n}, a_{2, n}, b_{2, n}, n=0(1) N-1$, which minimizes the mean square value of

$$
\sum_{n=0}^{N-1}\left[\sum_{i=1}^{2}\left\{a_{i, n} c_{i}(t)+b_{i, n} s_{i}(t)\right\} P_{n}(\theta, \lambda)\right]-\Delta H(\theta, \lambda, t)
$$

over the space and time parameters $(\theta, \lambda, t)$ determined by the altimetry. Here, $c_{i}$ and $s_{i}$ are the modulated harmonic functions defined by (4.6), with constants particular to tidal species $i$, and $P_{n}$, the computed Proudman functions of order $n$, including the 'constant' function of order zero and other values $n$ increasing with 'non-rotating frequency' of the eigenfunction (Sanchez et al., 1986).

By standard theory (4.8) gives rise to a set of normal linear equations for the $4 \mathrm{~N}$ parameters $\mathrm{a}_{\mathrm{i}, \mathrm{n}}, \mathrm{b}_{\mathrm{i}, \mathrm{n}}$ which are solved by inverting a non-singular matrix of order $4 \mathrm{~N} \times 4 \mathrm{~N}$. A sequence of trial values $\mathrm{N}$ were tried up to $N=100$, giving rise to pairs of variances $v_{i}(N)$, each being the contributions of the terms pertaining to tidal species $i$ to the total variance $V$ of $\Delta H$, when $N$ orders of Proudman functions are used. The residual variance of $(4.8)$ is $V-v_{1}-v_{2}$, and this, in general, decreases monotonically with $N$ toward an asymptote representing the residual noise in the data $\Delta \mathrm{H}$.

\section{Results}

Figure 8a shows the variance $v_{2}$, split into partial components $v_{c 2}, v_{s 2}$ associated with the functions $c_{2}(t), s_{2}(t)$ respectively, from solution of the complete set of normal equations from (4.8), with $N$ increasing from 5 to 100 in steps of 5 . The ratio $v_{c 2}: v_{s 2}$ depends on the time origin and is of no interest per se, but

$$
v_{c 2}+v_{s 2}=v_{2}
$$

would be independent of time and is the variance (scaled in $\mathrm{cm}^{2}$ ) contributed by semidiurnal terms. The total data variance $\mathrm{V}=2020 \mathrm{~cm}^{2}$.

As is usual in such least-squares fitting, the partial variances $\mathrm{v}$ increase rapidly for small values of $\mathrm{N}$, then increase more slowly. Occasional slight decreases of $\mathrm{v}$ with $\mathrm{N}$ are due to numerical deficiencies in the matrix inversion procedure. It is hard to decide exactly for which value of $\mathrm{N}$, further increase is unprofitable; ultimately, the addition of higher-order functions merely tries to fit noise in the data with increasing 'wiggliness'. A sign of over-fitting in this way is the appearance of large numerical values in the list of coefficients $a_{i, n}, b_{i, n}$. Taking this factor into account, as well as the values in Figure 8a, resulted in the choice of $\mathrm{N}=50$ as the largest reasonable compromise. 


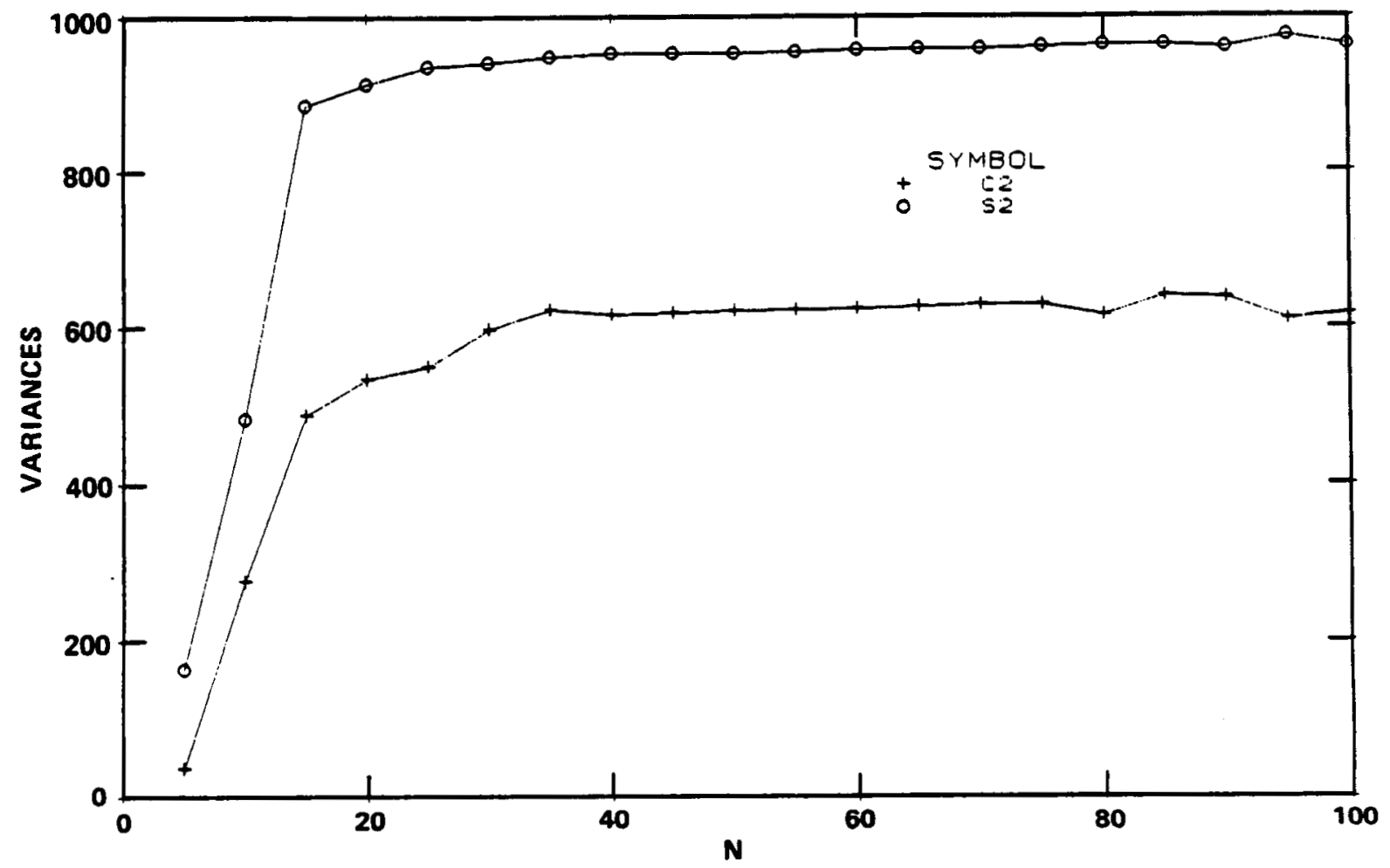

Figure 8a. The 'predictable parts' of the altimeter residual data variance of $2020 \mathrm{~cm}^{2}$ absorbed by fitting Proudman functions of order $\mathrm{O}$ to $\mathrm{N}-1$ according to (4.7). Crosses are variances associated with the harmonic functions $\mathrm{C}_{2}$; circles with $\mathrm{S}_{2}$, both related to the $\dot{M}_{2}$ tide. Scale in $\mathrm{cm}^{2}$.

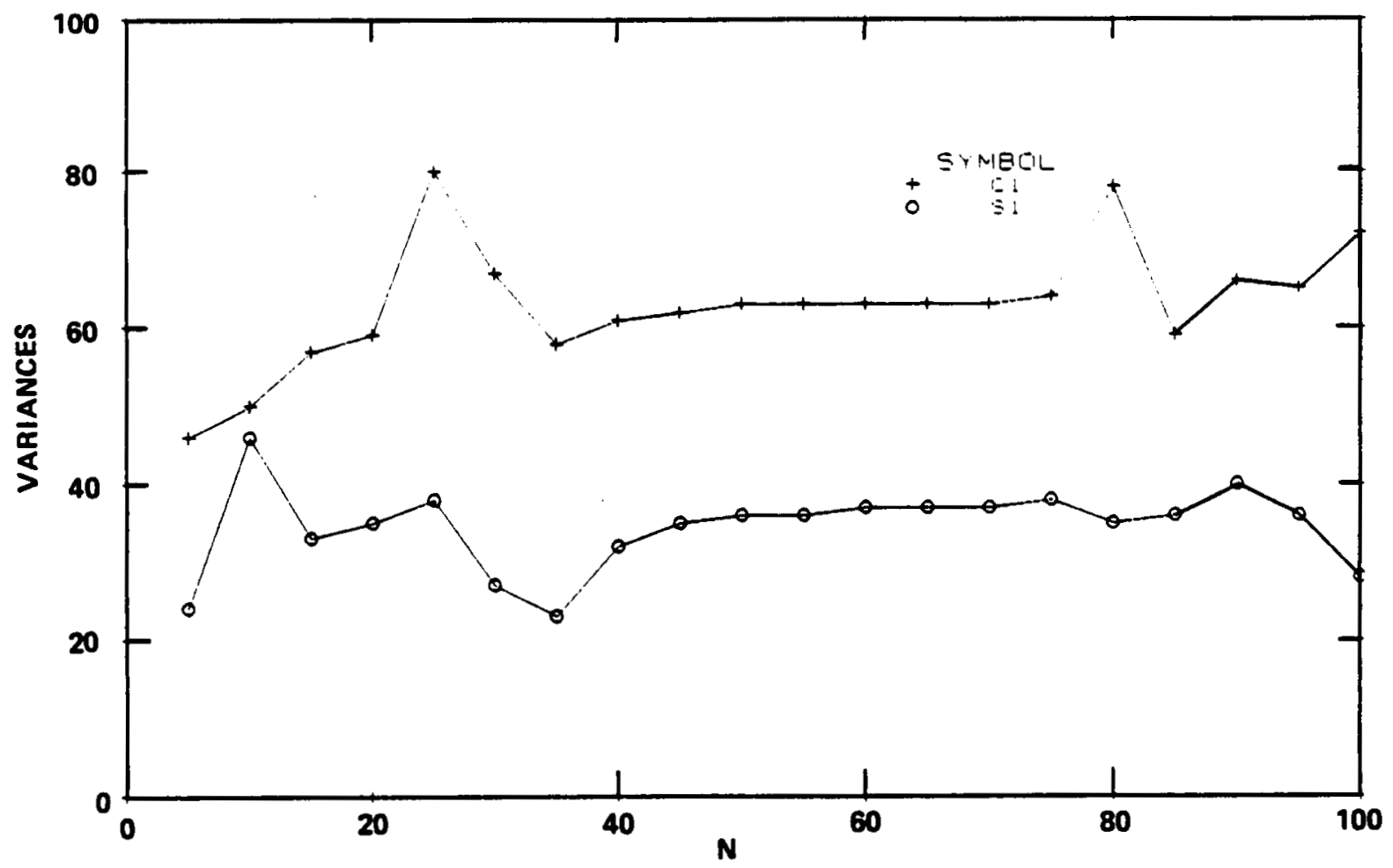

Figure $8 b$. Similar to $8 a$, but for $C_{1}, s_{1}$ related to the $0_{q}$ tide. 
The corresponding values $v_{c 1}, v_{s 1}$, for the diumal tide are depicted in Figure $8 b$, with scale increased by 10 . These $v_{1}$ components are appropriately much smaller than the $v_{2}$ components, and numerical noise is more evident at the larger scale. The large irregularities are clearly associated with similar irregularities in the $v_{2}$ variances, and are evidently compensating for them. However, the same sort of general increase of $v_{1}$ with $\mathrm{N}$ is apparent, and from similar reasoning, the choice $\mathrm{N}=50$ is a sensible compromise, giving

$$
v_{1}=99, v_{2}=1576, v-v_{1}-v_{2}=345 \mathrm{~cm}^{2} \text {. }
$$

If we had chosen $N=90$, which was also considered, the corresponding variances would be 106,1598 , and $316 \mathrm{~cm}^{2}$, respectively.

It is interesting that the diurnal variance $v_{1}$ is considerably less than the residual noise variance $v-v_{1}-v_{2}$. This is due to the space-time filtering implicit in the normal equations, and is analogous to the extraction of a small but significant peak from a spectrum of noisy data. The energy of a spectral peak may be much less than the total energy across the whole spectrum. In other words, the residual noise in this case is concentrated in much higher wave numbers and frequencies than can be accommodated by Proudman functions of order up to $n=100$ or thereabouts, with tidal periodicities.

The standard tidal amplitudes and (Greenwich) phase lags $H_{i}=(\theta, \lambda), G_{i}(\theta, \lambda)$ are given by

$$
H_{i}=\left(A_{i}^{2}+B^{2}\right)^{1 / 2} / f_{j}, G_{i}=\arctan \left(B_{i} / A_{i}\right)-\phi_{i}+\phi_{i}^{\prime}
$$

where $\left(A_{i}, B_{i}\right)=\sum_{n=0}^{N-1}\left(A_{i, n}, B_{i, n}\right) P_{n}(\theta, \lambda)$

and $f_{i}, \phi_{i}$ are the adjustments for conversion from $\Delta H$ to SSH $(4.2,4.3)$ with a small additional correction for the $18.6 \mathrm{y}$ modulation of the tide potential. $\phi_{\mathrm{i}}^{\prime}$ is the phase of the harmonic potential concerned, $0_{1}$ or $\mathrm{M}_{2}$, at the time $\mathrm{t}=0$ used in the computations.

Contour plots of $H_{i}, G_{i}$ computed by (4.9) from the solutions for $N=50$ are depicted in Figures $9 a$ and $9 \mathrm{~b}$. Comparison of Figure $9 \mathrm{a}$ with the Schwiderski model $\mathrm{M}_{2}$, (Figure 5a), shows a high degree of similarity; the principal features being two large zones of maximum amplitude near the Equator and two zones of even greater amplitude coastal maximum in the Gulfs of Panama and Alaska, interspersed with four central amphidromes and a nearly amphidromic minimum in the north near $190^{\circ} \mathrm{E}$. Figure $9 \mathrm{a}$ also reproduces the amphidrome east of Papua, New Guinea, but transforms the region of low amplitude southwest of Japan in Figure 5a into a true amphidrome. Schwiderski's map suggests that the two central maxima have about equal amplitude of $55 \mathrm{~cm}$. The SEASAT/Proudman function analysis gives the maximum near $230^{\circ} \mathrm{E}$ larger amplitude. The differences between Figures 5a and 9a are quite minor and neither can claim perfect accuracy anyway.

The satellite solution for $0_{1}$ (Figure $9 \mathrm{~b}$ ) again agrees in broad features with the Schwiderski solution (Figure 5b). This is even more remarkable, considering the generally lower amplitudes everywhere. We will not enlarge on the few points of dissimilarity, which are trivial. The fact that we can obtain any reasonable approximation to the $0_{1}$ map with the observed noise background is an excellent indication of the methods of analysis used, and promises well for future results from the much longer series of altimeter data now becoming available.

Comparison of the distribution of potential energy among the Proudman mode numbers $\mathrm{n}$ deduced from the above solutions with those presented in Table 6 is less satisfactory. Mode $n=4$, with rotational period $21.61 \mathrm{~h}$, again has the largest contribution to both $\mathrm{M}_{2}$ and $0_{1}$, and some of the other modes listed in Table 6 also appear in the top ten here, but with different ranks. Other modes appear in the present solution which do not appear in Table 6, and the distribution varies rather erratically with different values of 


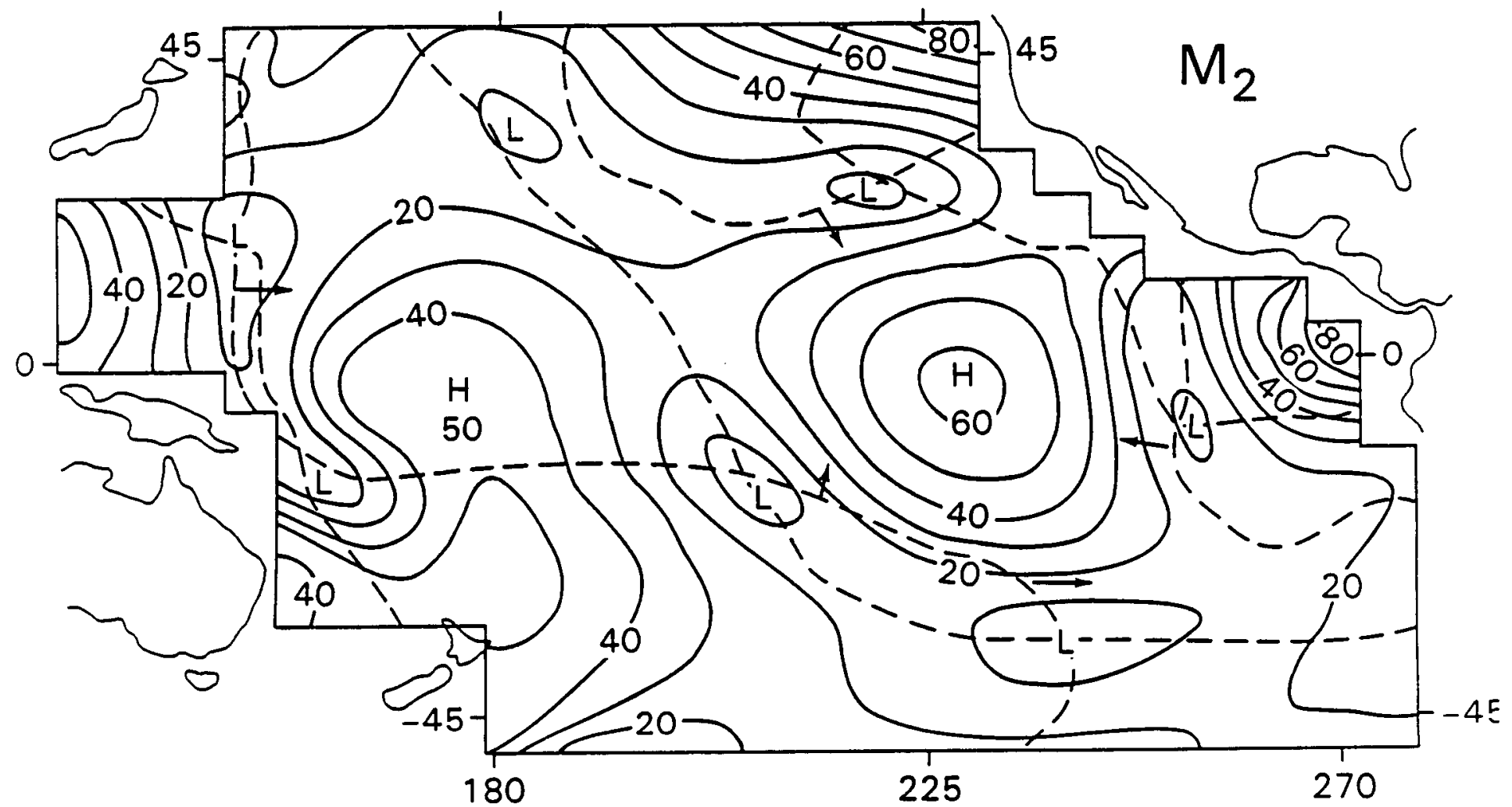

Figure 9a. $M_{2}$ tidal synthesis corresponding to 50 Proudman functions derived from altimeter height differences (4.2) over the reduced area of the Pacific Ocean shown. Solid lines show conventional tidal amplitude in $\mathrm{cm}$; broken lines show Greenwich phase lags at $90^{\circ}$ intervals. Arrows are attached to $0^{\circ}$ phase contours and indicate the sense of wave propagation around the amphidromes. H: local maxima; L: local minima (amphidromic if phase contours intersect).

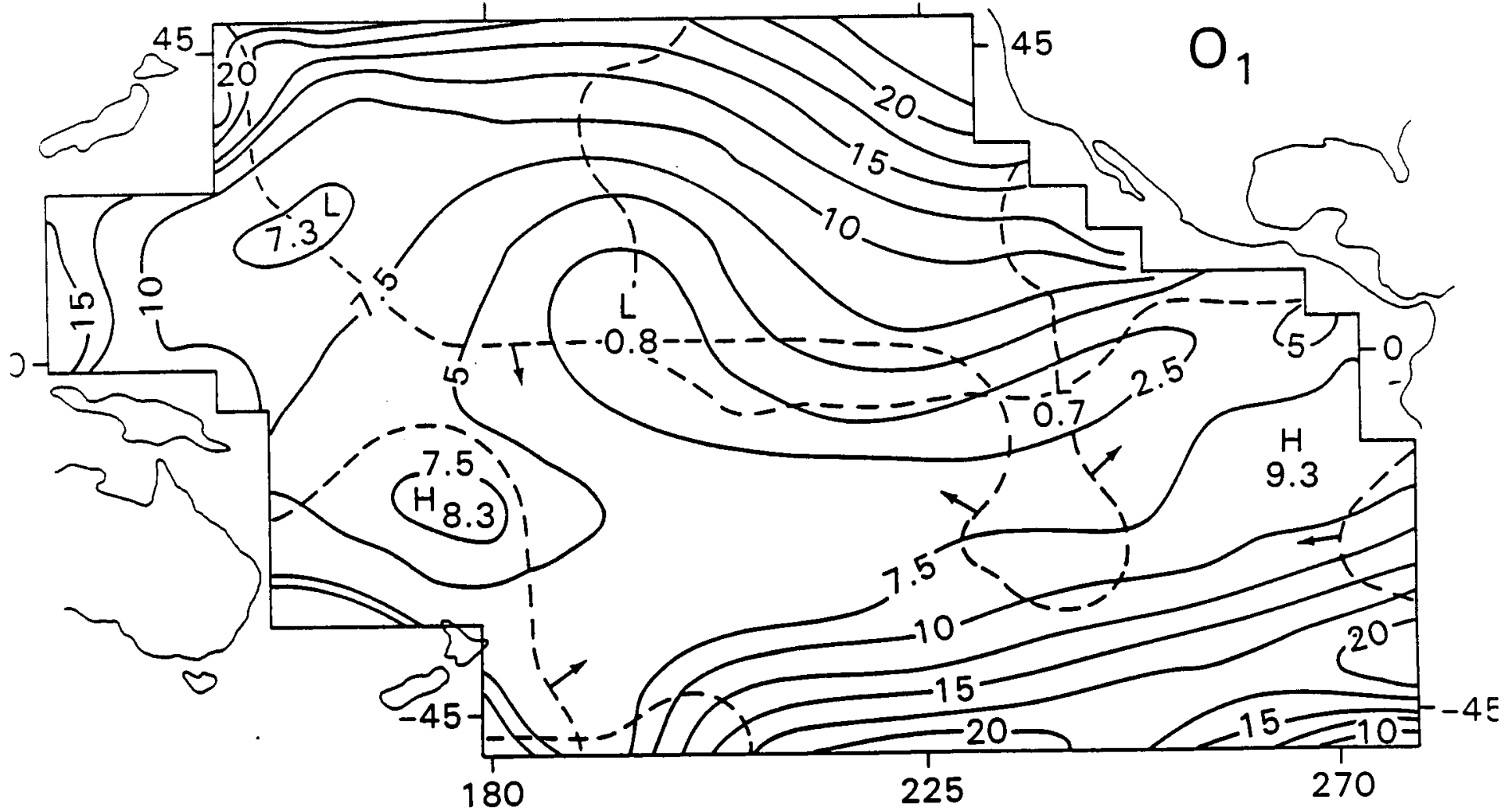

Figure 9b. Similar to Figure $9 a$, but for $0_{\mathfrak{q}}$. 
$\mathrm{N}$ in (4.8). The nonorthogonality of the Proudman functions over the reduced Pacific area used here, together with the noise background, must cause aliasing between different modes, making the distribution of potential energy with $\mathrm{n}$ being rather meaningless in this case.

\section{Expansion in Spherical Harmonics}

In order to assess the relative merits of expanding the tidal fields in Proudman functions and in spherical harmonics, we also analyzed the same altimetry data described in (4.1) through (4.3) by solving the normal equations for $a^{\prime}{ }_{n}, b^{\prime}{ }_{n}$, which minimize the mean square value of

$$
\sum_{n=0}^{H-1}\left[\sum_{i=1}^{2}\left\{a_{i, n}^{\prime} c_{i}(t)+b_{i, n}^{\prime} s_{i}(t)\right\}\right] Q_{n}(\theta, \lambda)-\Delta H(\theta, \lambda, t)
$$

where the modulated harmonic functions $c_{i}, s_{i}$ are the same as used in (4.8). $Q_{n}(\theta, \lambda)$ represents an ordered set of the real and imaginary parts of Associated Legendre Polynomials of degree 1, order $\mathrm{m}$,

$$
Q_{n} \equiv Y_{\ell m}(\theta, \lambda)=\left[\frac{2 \ell+1}{4 \pi} \cdot \frac{(\ell-m) !}{(l+m) !}\right]^{1 / 2} P_{\ell m}(\sin \theta) e^{i m \lambda}
$$

$P_{\ell m}(x)$ being the common Legendre polynomial, and the sequence of $(1, m)$ corresponding to $n=0,1,2, \ldots$ being

$$
(0,0)(1,0), R(1,1) I(1,1),(2,0) R(2,1) I(2,1), \ldots
$$

with $R$, I denoting real or imaginary parts. Complete coverage up to degree and order $\mathrm{k}-1$ requires $\mathrm{N}=\mathrm{k} 2$. Thus, $N=100$ covers harmonics up to degree and order 9 , while $N=50$ covers degree and order 6 with the addition of $\mathrm{Y}_{70}$.

The coefficients $a^{\prime}, b^{\prime}$ in (4.10) were solved in a very similar manner to $a, b$ in (4.8) using the same sequence of $\mathrm{N}$. Results for the partial variances $\mathrm{v}_{1}^{\prime}, \mathrm{v}_{2}^{\prime}$ are qualitatively similar to those for the analogous $v_{1}, v_{2}$, except that numerical variation with increasing $N$ is distinctly greater; probably due to greater correlation between spherical harmonics over the area considered-very much less than the whole sphere. However,

\begin{tabular}{|c|c|c|c|c|c|c|}
\hline \multirow[b]{2}{*}{$\mathbf{N}$} & \multicolumn{3}{|c|}{ Proudman Functions } & \multicolumn{3}{|c|}{ Spherical Harmonics } \\
\hline & $v_{1}$ & $v_{2}$ & $v_{1}+v_{2}$ & $v_{1}^{\prime}$ & $v^{\prime} 2$ & $v_{1}^{\prime}+v^{\prime}{ }_{2}$ \\
\hline 20 & 94 & 1449 & 1543 & 88 & 1275 & 1343 \\
\hline 40 & 93 & 1570 & 1663 & 93 & 1537 & 1630 \\
\hline 60 & 101 & 1582 & 1683 & 101 & 1560 & 1661 \\
\hline 80 & 103 & 1579 & 1682 & 101 & 1570 & 1671 \\
\hline 100 & 100 & 1579 & 1679 & 98 & 1584 & 1682 \\
\hline
\end{tabular}
$\mathrm{v}_{1}^{\prime}$ and $\mathrm{v}_{2}^{\prime}$ are, on the average, slightly less, as in the typical comparisons listed in Table 8.

Table 8. Comparison of Predicted Variances $\left(\mathrm{cm}^{2}\right)$

Whether the slight improvements in predicted variance achieved by fitting the same number $\mathrm{N}$ of Proudman functions are significant would be hard to say. Significant improvement must be felt mainly in the improved matching of the Proudman functions to the coastal configuration and bathymetry, but our reduced 
area excludes the regions where these factors are important for other reasons. Maps of $\mathrm{H}, \mathrm{G}$ computed from the coefficients $a^{\prime}, b^{\prime}$ look too similar to Figures $9 a$ and $9 b$ to be worth reproducing here, but there are qualitative signs that the advantage afforded by the Proudman function expansion is indeed in the sea areas close to the boundaries of the chosen area. Further experiments with longer altimeter data sets in other ocean areas will be needed before one can finally decide whether the advantages of Proudman functions outweigh the computational effort required to produce them.

\section{Conclusions}

This paper brings together two areas of research; one consisting of the computation of Proudman functions and their associated normal modes in large ocean basins (Sanchez et al., 1986), the other exploring methods of extraction of ocean tides from satellite altimetric data (Woodworth and Cartwright, 1986).

The Pacific Ocean, considered here as a closed basin, has the usual wide spectrum of eigenfrequencies, with gravitational natural periods from $43.9 \mathrm{~h}$ to $3.5 \mathrm{~h}$. Some of the normal modes spatially resemble those computed by Platzman, et al. (1981) for a global ocean, although closure of the connected region encircling Antarctica prevents too close a comparison in frequency.

As in other approaches to tidal modeling, the diurnal and semidiurnal maps resulting from direct dynamic solution are only qualitatively good, partly due to the lack of friction and other unmodeled physical factors. Much closer agreement with the known features of the ocean tidal maps is obtained when the Proudman functions are constrained to a least-squares fit to empirical data, as represented by Schwiderski's models. It might be suggested that the degree of fit with 200 Proudman functions shown in Figures $6 \mathrm{a}$ and $6 \mathrm{~b}$ could be matched with any set of orthogonal spatial functions, but Table 4 shows that the approximation is much better than with an equivajent number of spherical harmonics. This result clearly reflects the advantages of using the kinematic constraints embodied in the Proudman functions, which are totally lacking in spherical harmonics.

Modeling the tidal signal in the altimetry by Proudman functions is more limited by the noise level of the data, but the maps obtained with only 50 functions, (Figures $9 \mathrm{a}$ and $9 \mathrm{~b}$ ), are encouragingly close to the Schwiderski maps based on tide-gauge data, and are marginally but significantly better than the fit with the same number of spherical hamonics. It is particularly encouraging to see a plausible map for the low amplitude $0_{1}$ component emerge from barely 17 days of SEASAT altimetry. Several months of altimetric data were previously thought to be necessary to separate the aliased diurnal and semidiurnal constituents. The present result must be at least partially due to the improved methods of geoidal and orbital noise reduction employed here. In general, these results promise well for future applications of similar methods to altimetric data of much longer duration (GEOSAT, ERS-1, TOPEX-POSEIDON), using Proudman functions computed for the global ocean.

\section{ACKNOWLEDGMENTS}

We would like to thank Melissa Harper, Beatrice Boccucci, and Donna Hollar of Goddard Space Flight Center, for providing efficient secretarial support. We express our appreciation to Dr. Ronald Estes of SAR for providing us with the software used in the spherical harmonics computations, to Dr. Clyde Goad (formerly with NGS) for providing the tape containing Schwiderski's tidal solution, and Dr. Oscar Colombo of EG\&G for providing an edited file of SEASAT altimetry. Maria Purchell of SAR gave valuable assistance with the altimeter computations. Stephen D. Steenrod of ARC provided some of the computer software. 


\section{REFERENCES}

Brown, R.D. and M.K. Hutchinson, 1981. Ocean tide determination from satellite altimetry. In Oceanography from Space, pp. 897-906, ed. Gower, J.F.R. Plenum Press, New York.

Cheney, R.D., Marsh, J.G. and B.D. Beckley, 1983. Global mesoscale variability from collinear tracks of SEASAT altimeter data. J. Geophys. Res. 18 , (C7), 4343-4354.

Christensen, N., 1973. On free modes of oscillation of a hemispherical basin centered on the Equator. $J$. Mar. Res., $31,3,168-174$.

Colombo, O.L., 1984. Altimetry, orbits and tides. NASA Goddard Space Flight Center, Technical Memorandum, TM 86180.

Gotlib, V.Y. and B.A. Kagan, 1982. Numerical simulation of tides in the world oceans: 1. Parameterization of shelf effects. Deutsche Hydrogr. Z. 34, 273-283.

Gotlib, V.Y. and B.A. Kagan, 1982. Numerical simulation of tides in the world oceans: 2. Experiments on the sensitivity of the solution. Deutsche Hydrogr. Z. $35,1-14$.

Longuet-Higgins, M.S., 1968. The eigenfunctions of Laplace's tidal equations over a sphere. Phil. Trans. $R$. Soc. London, A262, $511-607$.

Longuet-Higgins, M.S. and G.S. Pond, 1970. The free oscillations of fluid on a hemisphere bounded by meridians of longitude. Phil. Trans. R. Soc. London, A266, 193-223.

Luther, D.S., 1983. Why haven't you seen an ocean mode lately? Ocean Modeling, 50, 1-6.

Mazzega, P., 1985. M 2 model for the global ocean tide derived from SEASAT altimetry. Mar. Geod. 9. $335-363$.

Parke, M.E. and M.C. Hendershott, 1980. $\mathrm{M}_{2}, \mathrm{~S}_{2}, \mathrm{~K}_{1}$ models of the global ocean tide on an elastic Earth. Mar. Geod. 3, 379-408.

Parke, M.E. and D.B. Rao (Eds.) 1983. Report on the NASA Workshop on tidal research. JPL Publication 83-71, Pasadena, CA.

Platzman, G.W., 1978. Normal modes of the world ocean. I. Design of a finite element baratropic model. J. Phys. Oceanogr. ㅈ, 3, 323-343.

Platzman, G.W., 1984. Normal modes of the world ocean. III. Procedure for tidal synthesis; IV. Synthesis of diumal and semidiurnal tides. J. Phys. Oceanogr. 14, 10, 1521-1550.

Platzman, G.W., G.A. Curtis, K.S. Hansen and R.D. Slater, 1981. Normal modes of the world ocean. Part II: Description of modes in the period range 8-80 hours. J. Phys. Oceanogr. 11, 5, 579-603.

Proudman, J., 1918. On the dynamical equations of the tides, Parts I, II, III. Proc. London Math. Soc. 18, $1-68$.

Rao, D.B., 1966. Free gravitational oscillations in rotating rectangular basins. J. Fluid Mech. 25, 523-555.

Sanchez, B.V., D.B. Rao, and P.G. Wolfson, 1985. Objective analysis for tides in a closed basin. Mar. Geod. $\underline{9}$, $1,71-91$.

Sanchez, B.V., D.B. Rao and S.D. Steenrod, 1986. Tidal estimation in the Atlantic and Indian Oceans. Mar. Geod. 10, 3/4, 309-349. 
Schwab, D.J. and D.B. Rao, 1983. Barotropic oscillations of the Mediterranean and Adriatic Seas.; Tellus, $\underline{35 \mathrm{~A}}, 417-427$.

Schwiderski, E.W., 1983. Atlas of ocean tidal charts and maps, I. The semidiurnal principal lunar tide $\mathrm{M}_{2}$. Mar. Geod. 6, 3/4, 219-265.

Sundermann, J., 1977. The semidiumal principal lunar tide in the Bering Sea. Deutsche Hydrogr. Z. $\underline{30}$, 91-101.

Webb, D.J., 1980. Tides and tidal friction in a hemispherical ocean centered at the Equator. Geophys. J.R. astr. Soc. 61, 573-600.

Woodworth, P.L. and D.E. Cartwright, 1986. Extraction of the $\mathbf{M}_{2}$ ocean tide from SEASAT altimeter data. Geophys. J.R. astr. Soc., 84, 227-255.

Wubber, Ch. and W. Krause, 1979. The two-dimensional seiches of the Baltic Sea. Oceanologica Acta, 2, 4, $435-446$. 


\begin{tabular}{|c|c|c|c|c|}
\hline \multicolumn{5}{|c|}{ Report Documentation Page } \\
\hline $\begin{array}{l}\text { 1. Report No. } \\
\text { NASA TM-100694 }\end{array}$ & \multicolumn{2}{|c|}{ 2. Government Accession No. } & \multicolumn{2}{|c|}{ 3. Recipient's Catalog No. } \\
\hline \multirow{2}{*}{\multicolumn{3}{|c|}{$\begin{array}{l}\text { 4. Title and Subtitle } \\
\text { TIDAL ESTIMATION IN THE PACIFIC WITH } \\
\text { APPLICATION TO SEASAT ALTIMETRY }\end{array}$}} & \multicolumn{2}{|c|}{$\begin{array}{l}\text { 5. Report Date } \\
\text { DECEMBER } 1987\end{array}$} \\
\hline & & & \multicolumn{2}{|c|}{$\begin{array}{l}\text { 6. Performing Organization Code } \\
621\end{array}$} \\
\hline \multirow{2}{*}{\multicolumn{3}{|c|}{$\begin{array}{l}\text { 7. Author(s) } \\
\text { Braulio V. Sanchez and David E. Cartwright }\end{array}$}} & \multicolumn{2}{|c|}{$\begin{array}{l}\text { 8. Performing Organization Report No. } \\
88 \mathrm{~B} 0061\end{array}$} \\
\hline & & & \multicolumn{2}{|l|}{ 10. Work Unit No. } \\
\hline \multirow{2}{*}{\multicolumn{3}{|c|}{$\begin{array}{l}\text { 9. Performing Organization Name and Address } \\
\text { Goddard Space Flight Center } \\
\text { Greenbelt, Maryland } 20771\end{array}$}} & \multirow{2}{*}{\multicolumn{2}{|c|}{ 11. Contract or Grant No. }} \\
\hline & & & & \\
\hline \multirow{2}{*}{\multicolumn{3}{|c|}{$\begin{array}{l}\text { 12. Sponsoring Agency Name and Address } \\
\text { National Aeronautics and Space Administration } \\
\text { Washington, D.C. } 20546-0001\end{array}$}} & \multicolumn{2}{|c|}{$\begin{array}{l}\text { 13. Type of Report and Period Covered } \\
\text { Technical Memorandum }\end{array}$} \\
\hline & & & \multicolumn{2}{|c|}{ 14. Sponsoring Agency Code } \\
\hline \multicolumn{5}{|c|}{ David E. Cartwright is affiliated with the National Academy of Sciences, Washington, D.C. } \\
\hline \multicolumn{5}{|c|}{$\begin{array}{l}\text { The techniques for computing the eigenfunctions of the velocity potential (Proudman functions) set out in } \\
\text { Sanchez, et al. (1986) in relation to the Atlantic-Indian Oceans are here applied to the Pacific Ocean, using a } 6^{\circ} \times 6^{\circ} \\
\text { grid of } 510 \text { points ( } 455 \text { points for the associated stream functions). Normal modes are computed from the first } \\
150 \text { Proudman functions and have natural periods from } 43.9 \mathrm{~h} \text { downward. Tidal syntheses are derived from these } \\
\text { modes by direct application of the (frictionless) dynamic equations and by least-squares fitting of Proudman func- } \\
\text { tions to the dynamically interpolated tide-gauge data of Schwiderski (1983). The modes contributing the most } \\
\text { energy to the principal harmonic tidal constituents are different in the two computations: their natural periods are } \\
\text { typically in the range of } 9-16 \mathrm{~h} \text { for semidiumal, and } 1443 \mathrm{~h} \text { for diurnal tides. The rms of fit for Proudman functions } \\
\text { is, in all cases, better than the corresponding value for the same number of spherical harmonics. } \\
\text { Before fitting the Proudman functions to the altimetry from the } 3 \text {-day repeat cycle of SEASAT, the data are } \\
\text { processed by novel methods. The geoid component is eliminated by taking collinear differences at a fixed time-lag } \\
\text { of } 2 \text { repeat cycles. Orbit errors are reduced by extracting the } 1 \text { rev }-1 \text { component at every ascending node; this com- } \\
\text { ponent varies slowly and nonlinearly in time. The spatial fitting process includes } \mathrm{M}_{2} \text { and } 0_{1} \text { frequencies, both of } \\
\text { which emerge with significant and realistic tidal mapping, but residual noise in the data limits the number of Proud- } \\
\text { man functions to about } 50-60 \text { before showing signs of 'over-fitting". Fitting the same data by spherical harmonics } \\
\text { gives marginally lower predicted variance for the same number of parameters. }\end{array}$} \\
\hline \multirow{2}{*}{\multicolumn{2}{|c|}{$\begin{array}{l}\text { 17. Key Words (Suggested by Author(s)) } \\
\text { Tides, Estimation, Pacific, SEASAT, } \\
\text { Altimetry, Normal Modes, Proudman } \\
\text { Functions }\end{array}$}} & \multirow{2}{*}{\multicolumn{3}{|c|}{$\begin{array}{l}\text { 18. Distribution Statement } \\
\text { Unclassified-Unlimited } \\
\text { Subject Category } 48\end{array}$}} \\
\hline & & & & \\
\hline $\begin{array}{l}\text { 19. Security Classif. (of this report) } \\
\text { UNCLASSIFIED }\end{array}$ & $\begin{array}{l}\text { 20. Sec } \\
\text { UN }\end{array}$ & is page) & 21. No. of pages & 22. Price \\
\hline
\end{tabular}

